Christian Hueppe, Jasmin Geppert, Rainer Stamminger, Hendrik Wagner, Heike Hoelscher, Jadran Vrabec, Andreas Paul, Andreas Elsner, Wolfgang Becker, Ulrich Gries, Alfred Freiberger

\title{
Age-related efficiency loss of household refrigeration appliances: Development of an approach to measure the degradation of insulation properties
}

Journal article | Accepted manuscript (Postprint)

This version is available at https://doi.org/10.14279/depositonce-9913

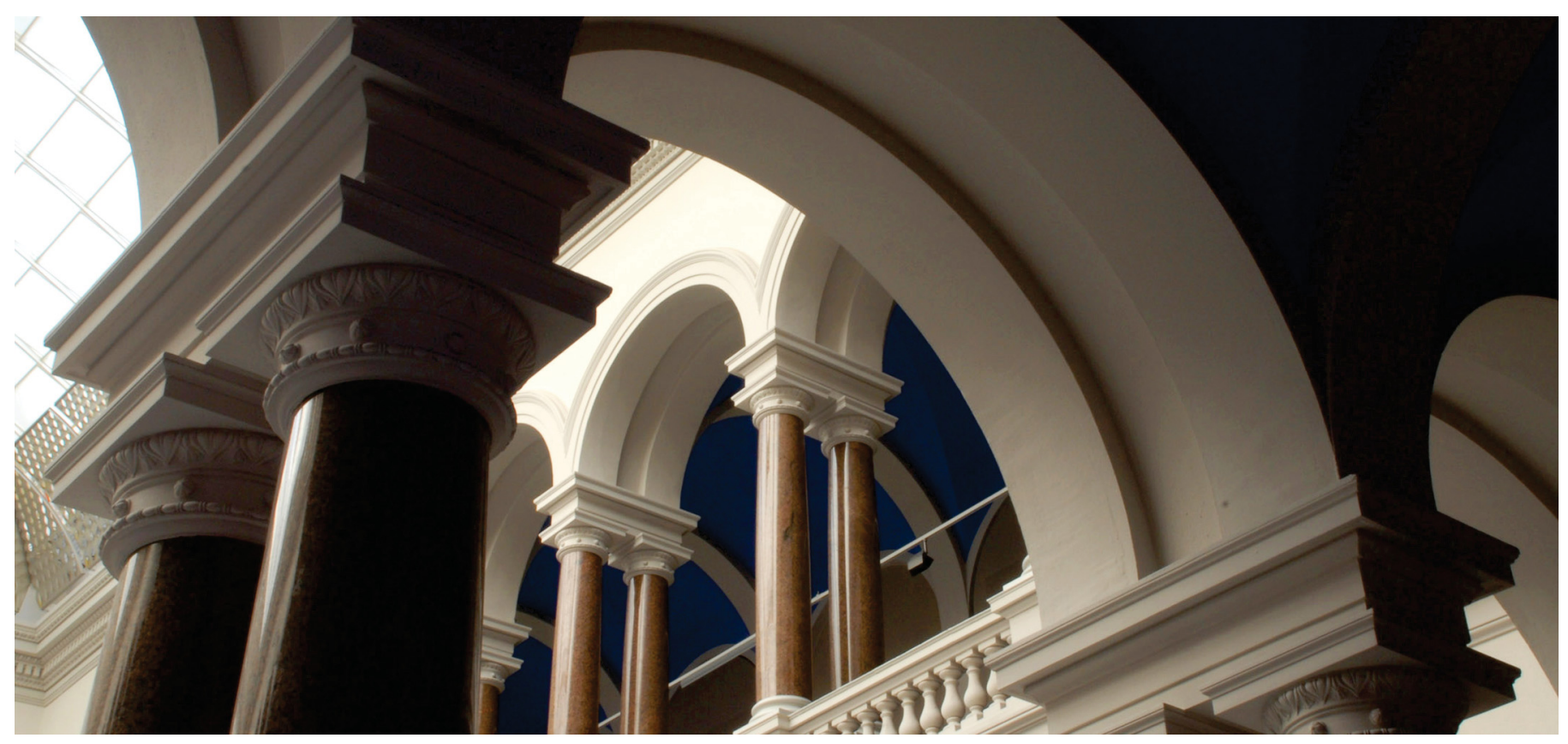

Hueppe, C., Geppert, J., Stamminger, R., Wagner, H., Hoelscher, H., Vrabec, J., Paul, A., Elsner, A., Becker, W., Gries, U., \& Freiberger, A. (2020). Age-related efficiency loss of household refrigeration appliances: Development of an approach to measure the degradation of insulation properties. Applied Thermal Engineering, 173, 115113. https://doi.org/10.1016/j.applthermaleng.2020.115113 
Accepted manuscript of: Hueppe, C., Geppert, J., Stamminger, R., Wagner, H., Hoelscher, H., Vrabec, J., Paul, A, Elsner, A., Becker, W., Gries, U., Freiberger, A. (2020). Age-related efficiency loss of household refrigeration appliances: Development of an approach to measure the degradation of insulation properties. Applied Thermal Engineering, 173, 115113.

https://doi.org/10.1016/j.applthermaleng.2020.115113

This manuscript version is made available under the CC-BY-NC-ND 4.0 license

http://creativecommons.org/licenses/by-nc-nd/4.0/

\section{Age-related efficiency loss of household refrigeration appliances: development of an approach to measure the degradation of insulation properties}

Christian Hueppe ${ }^{\mathrm{a},{ }^{*}}$, Jasmin Geppert ${ }^{\mathrm{a}}$, Rainer Stammingera, Hendrik Wagner ${ }^{\mathrm{b}}$, Heike Hoelscher $^{\mathrm{b}}$, Jadran Vrabec ${ }^{c}$, Andreas Pauld, Andreas Elsner ${ }^{\mathrm{d}}$, Wolfgang Beckere, Ulrich Gries ${ }^{f}$, Alfred Freiberger ${ }^{9}$

a

b

d

e

f Nidec Global Appliance Germany GmbH, Mads-Clausen-Str. 7, 24939 Flensburg Germany

Ulrich.Gries@mail.nidec.com

g SECOP Austria GmbH, Jahnstraße 30, 8280 Fürstenfeld - Austria

A.Freiberger@secop.com
Corresponding author:

Phone:

Fax:

Mail:
Christian Hueppe

University of Bonn, Institute of Agricultural Engineering -

Section Household and Appliance Engineering

Nussallee 5, 53115 Bonn - Germany

$+49228 / 733046$

+49 228/732596

chueppe@uni-bonn.de 


\section{Nomenclature:}

Bonn method Testing procedure of the insulation properties

\section{ABS}

HIPS

E1

E2

$K$

PUR

VIP

$X P S$

$R^{2}$

$A$

$A_{m}$

$x_{c c}$

$x_{f c}$

$y_{c c}$

$y_{f c}$

$z_{c c}$

$z_{f c}$

$d$

$d_{x i}$

$d_{y i}$

$E C$

$\dot{Q}$

$C_{V}$

$k$

$k_{\text {calculated }}$

$\lambda$

$\lambda_{P U R}$

$\lambda_{X P S}$

$\alpha_{i}$

$\alpha_{a, i}$

$\alpha_{a}$

$\alpha_{a, m}$

$\tau_{I}$

$\tau_{I}(t)$

$T_{a}$

$T_{a}(0)$

$T_{a}(t)$

$T_{i}$

$T_{i}$ measured

$T_{i}(0)$

$T_{i}(t)$

$\Delta T_{s, a}$

$\Delta T_{s, i}$ of domestic refrigeration appliances

Acrylonitrile butadiene styrene

High impact polystyrene

First layer of additional insulation

Second layer of additional insulation

Kelvin

Polyurethane foam insulation

Vacuum insulation panel

Extruded polystyrene foam

Coefficient of determination

Cross-sectional surface area $\left(\mathrm{m}^{2}\right)$

Cross-sectional surface area of a specific wall surface $\left(\mathrm{m}^{2}\right)$

Width of the cooling compartment $(\mathrm{cm})$

Width of the freezer compartment $(\mathrm{cm})$

Height of the cooling compartment $(\mathrm{cm})$

Height of the freezer compartment $(\mathrm{cm})$

Depth of the cooling compartment $(\mathrm{cm})$

Depth of the freezer compartment $(\mathrm{cm})$

Material thickness $(\mathrm{mm})$

Thickness of the multi-layered compartment inside wall $(\mathrm{mm})$

Thickness of the multi-layered compartment outside wall $(\mathrm{mm})$

Electricity consumption $(W h)$

Heat flow through (composite) compartment walls $(W)$

Isochoric heat capacity $(\mathrm{J} / \mathrm{K})$

Heat transfer coefficient $\left(W /\left(m^{2} * K\right)\right)$

Calculated heat transfer coefficient $\left(W /\left(m^{2} * K\right)\right)$

Thermal conductivity $(W /(m * K))$

Thermal conductivity of polyurethane foam insulation $(W /(m * K))$

Thermal conductivity of extruded polystyrene foam $(W /(m * K))$

Heat transition coefficient at inner compartment surface $\left(W /\left(m^{2} * K\right)\right)$

Heat transition coefficient at a specific inner compartment surface $\left(W /\left(m^{2} * K\right)\right)$

Heat transition coefficient at outside compartment surface $\left(W /\left(m^{2} * K\right)\right)$

Heat transition coefficient at a specific outside compartment surface $\left(W /\left(m^{2} * K\right)\right)$

Test value of the Bonn method $\left(\mathrm{min}^{-1}\right)$

Test value at time $t$ within the test interval $\left(\mathrm{min}^{-1}\right)$

Ambient temperature $\left({ }^{\circ} \mathrm{C}\right)$

Ambient temperature at the start of the test interval $\left({ }^{\circ} \mathrm{C}\right)$

Ambient temperature at time $t$ within the test interval $\left({ }^{\circ} \mathrm{C}\right)$

Internal compartment temperature $\left({ }^{\circ} \mathrm{C}\right)$

Internal compartment temperature measured within the test interval $\left({ }^{\circ} \mathrm{C}\right)$

Internal compartment temperature at the start of the test interval $\left({ }^{\circ} \mathrm{C}\right)$

Internal compartment temperature at time $t$ within the test interval $\left({ }^{\circ} \mathrm{C}\right)$

Temperature gradient at outer surface $(K)$

Temperature gradient at inner surface $(K)$ 


\begin{abstract}
:
Despite the omnipresence of household refrigeration appliances, there is still a lack of knowledge about their age-related efficiency loss over time. Past studies provide basic evidence for increasing electricity consumption of cooling appliances with ageing but fail to investigate the associated technical wear. Concentrating on the degradation of the thermal insulation, we first determined the ageing process of sealed samples of polyurethane rigid foam by investigating changes in cell gas composition and thermal conductivity over time. Simultaneously, the main challenge was to develop an approach that investigates the age-related efficiency loss of the insulation without destruction. This testing procedure is referred to as the Bonn method. The non-destructive Bonn method was applied to varying refrigerator models in a series of successive experiments to evaluate the insulation degradation over time. Subsequently, the physical relationship between the test value of the Bonn method and the heat transfer through the multi-layered compartment walls of domestic refrigeration appliances was established, ultimately characterising the degrading insulation in terms of increasing heat transfer. Our results give substantiated evidence that the efficiency loss of cooling appliances is greatly influenced by insulation degradation over time. The ageing of sealed samples of polyurethane rigid foam indicates a large initial increase in thermal conductivity by $15 \%$ within the first year, corresponding to a change in cell gas composition. These results are in line with those of the Bonn method, emphasising an increasing heat flow through the multi-layered compartment walls of domestic refrigerators with ageing. Therewith, the present study is of significance to a wide range of stakeholders and forms the basis for future research.
\end{abstract}

\title{
Keywords:
}

Household refrigerators; Aging; Insulation degradation; Test method; Heat transfer

\section{Introduction:}

Domestic cooling appliances are an integral part of our everyday life and are viewed as standard household commodities. However, the market development for refrigeration appliances is regionally diverse and offers a wide range of different cooling technologies [[1]. The ownership, referring to the total stock over households, in less urbanised countries, such as Peru, was only $45 \%$ in 2014 , whereas the ownership in the People's Republic of China almost quadruplicated to $90 \%$ between 1994 and 2014 [2]. By contrast, the ownership in many European countries often exceeds one appliance per household. Compared to emerging economies, sales in these countries mainly base on replacement with new appliances, motivated by electricity consumption $(E C)$ savings and environmental issues $[[1,[3,[4]$. However, despite the omnipresence of domestic cooling appliances, there is still a lack of knowledge about their age-related efficiency loss over time. This is even more surprising, as a high level of political pressure to reduce the $E C$ of refrigeration models exists, for 
instance, via energy labelling and eco-design measures [5]. Such policy initiatives prompted technological progress and increased the efficiency of new appliances throughout the last decades. Regulations and directives pushed and pulled the market towards more efficient appliances, which is generally why stock appliances consume more than newer models [6,[7]. Despite these efforts, little attention has been paid to the fact that the efficiency of refrigeration appliances starts to deteriorate right after the production process $[8,[9]$. Consequently, a profound understanding of the deterioration of domestic cooling appliance's efficiency throughout their lifetime does not exist up to date. A better understanding of the degradation is thus a critical topic for policy makers, consumers and manufacturers alike.

\subsection{Degradation of domestic refrigeration appliances over time}

To date, limited research has been conducted on the degradation of household refrigeration appliances over time. Previous studies indicated that next to the construction, room temperature, consumer behaviour and age impact the $E C$ of refrigeration appliances [10,[11]Fehler! Verweisquelle konnte nicht gefunden werden.. Harrington et al. [12] discovered that more than $15 \%$ of the total EC of domestic refrigerators and freezers is due to user interactions. These include day-to-day door openings, the loading of appliances and the impact of room temperature [12]. A survey study conducted by Geppert et al. [13] regarding the influence of consumer behaviour on the EC further found that $25 \%$ of household refrigeration appliances across Europe operate outside their temperature ranges specified by the climatic classes [13]. However, besides consumer interactions, ageing leads to efficiency loss over time. From a technical point of view, refrigeration appliances are systems that are subject to technical wear throughout their use phase. Biglia et al. [14] conducted a large-scale survey in which 998 cold appliances were monitored in 766 properties in England in 2017. One finding was that the average specific $E C\left(\mathrm{kWh} / \mathrm{m}^{3}\right.$ year) increased significantly for appliances older than 11 years, as compared to younger appliances [14]. Although Biglia et al. [14] did not attempt to explain the sources of over-consumption, the study showed that appliances older than 11 years disproportionally often suffered from technical wear. Among the sources responsible for overconsumption were broken thermostat controllers, distorted door gaskets and wet insulations. Similar findings were made by Isaacs et al. [15] in New Zealand when monitoring the $E C$ of 400 randomly selected houses. Refrigeration appliances accounted for $15 \%$ of total household electricity, but $7 \%$ of all appliances monitored were found faulty and $9 \%$ operated marginally [15]. Greenblatt et al. [16] further examined the $E C$ of 1,467 domestic refrigerators from seven studies over a period of 18 years and conducted multiple regression analysis to specifically show changes in consumption patterns over time. An average annual increase in consumption between 1-2 \% was concluded [16]. However, while this study shows a degradation of appliance's $E C$ with progressive use, uncertainty exists due to a lack of control for user interactions, ambient conditions and the actual operational state of the monitored appliances. Different from other studies, the German Foundation for Product Testing and Consumer's Association (Stiftung Warentest) [17] conducted in-depth research on the EC of three different refrigeration appliances over a course of 18 years, between 1994 and 2012. The EC of different appliances was measured under standardised laboratory conditions after 3 years and 18 
years, respectively. One important finding of this study was that the $E C$ of all appliances increased at least by $20 \%$ within the investigation period. Another finding was that the change in $E C$ was most pronounced within the first years of investigation $\quad[17,[18]$. Unlike previous studies that based on data gathering in the field, the controlled test conditions of this study allowed to assume that the degradation of the foam insulation is a dominant factor on increasing $E C$ over time [17,[18]. In fact, the effectiveness of foam insulations is highest only after the production process and diminishes from the initial state with progressive use $[8,[9]$. However, differences concerning the ageing of foam insulations produced with varying blowing technologies may exist, especially for previously used trichlorofluoromethane (CFC-11) and its nowadays commonly used substitutes [19-[21].

Although past studies indicate an ageing-based efficiency loss over time, many failed to investigate the actual reasons. Technical wear affecting system components has rarely been considered to have an impact on the efficiency loss with progressive use and, as a consequence, was not the main focus of previous research [22]. The share of varying system components' degrading impact on changing consumption patterns is thus still unknown and the challenge is to identify which component causes which degree of efficiency loss over time [23-[26]. However, neither comprehensive research on the relation between degrading foam insulation and refrigeration appliance's efficiency loss over time exists, nor appropriate testing methods to determine the degradation of built-in insulation materials without destruction. This contribution intends to close this research gap.

\subsection{Characteristics and operational properties of foam insulations}

Polyurethane (PUR) rigid foam is commonly used as a thermal insulation for domestic refrigeration appliances. PUR, like other foam insulations, is divided into two groups, either with open or closedcells. Open-cell foams are distinguished by a high degree of porosity due to the permeability of the cell structure, whereas the cell matrix in closed-cell foams is impermeable and has a more rigid form. Both foam insulations are characterised by their density [[9], with closed-cell PUR foam commonly used for refrigeration appliances. Foams of high density are created by the expansion of the blowing agent, preventing cells from developing open connections with each other and enclose cell gases within the cell membrane $[[9,[27]$. Consequently, closed-cell foam insulations have a higher density than open-cell insulations with roughly $32-48 \mathrm{~kg} / \mathrm{m}^{3}$ compared to $8 \mathrm{~kg} / \mathrm{m}^{3}$, respectively [[9,[28]. Since the thermal conductivity $(\lambda)$ of insulation materials partially depends on the material density and porosity, closed-cell insulations typically perform around $0.025 \mathrm{~W} /(m * K)$, compared to open-cell insulations with a $\lambda$ around $0.036 \mathrm{~W} /(m * K)[[9,[29]$. The $\lambda$ is a measure of a material's effectiveness in conducting heat, thus, in the light of thermal performance, an important property of the refrigerator foam insulation [29]. The structure of the cell matrix determines the heat flux and the $\lambda$ of the insulation material to a large extent. In closed-cell foams, for instance, the insulation effect originates from the cellular gas within the cells. Due to the impermeability, cell gas is prevented from moving and convective heat transfer is suppressed [28]. Due to the structure finish of closed-cell PUR foam matrix, the effect of radiative heat exchange across the insulation is small [30]. Plastic foam insulations, such as PUR and polystyrene, commonly use fluorocarbon gases (PFCs) within the cells 
to obtain a low $\lambda$ performance $[28,[30,[31]$. However, the operational properties of foam insulations start to deteriorate right after the manufacturing $[8,[9]$.

\subsubsection{Ageing effects of the foam insulation}

Previous studies investigating ageing effects of foam insulations assumed the diffusion of blowing agents out of the cells and related changes in gas composition to be a main cause for reduced thermal performance $[[9,[30,[32,[33]$. Therefore, the age-related efficiency loss of $P U R$ was mostly investigated based on cell gas composition and microstructural analysis in past studies [34-[36]. Albrecht and Khoukhi et al. [37-[39] and Glouannec et al. [40] for example, conducted comprehensive research on the ageing of PUR rigid foam resulting from gas changes over time. Due to concentration differences between the inside of the cells and the ambient, cell gas diffuses out of the insulation and is replaced by ambient air and water vapour [41]. A gradual diffusion process leads to a rise in the thermal conductivity of PUR $\left(\lambda_{P U R}\right)$ and impairs the properties of the insulation $[42,[43]$. Gas diffusion rates depend not only on the concentration gradient but also on the tendency of each gas species to diffuse through the matrix, characterised by a diffusion coefficient $[44,[45]$.

However, besides the diffusion process, the ambient temperature $\left(T_{a}\right)$ and moisture content are relevant factors degrading insulation properties with progressive use. Budaiwi et al. [29] investigated the $\lambda$ of 32 insulation samples, differing in type, terms of insulating property, facing and intended application. The $\lambda$ of tested samples were measured at five different operating mean temperatures ranging from $4{ }^{\circ} \mathrm{C}$ to $43^{\circ} \mathrm{C}$. Results indicated that various types of insulation material react differently when exposed to high $T_{a}$, also depending on the used facing materials [30]. Wilkes et al. [46-[48] investigated the degradation of PUR foam insulation in simulated refrigerator panels by determining changes in $\lambda_{P U R}$. Test specimens were exposed to varying $T_{a}$ of $90^{\circ} \mathrm{F}\left(32.2^{\circ} \mathrm{C}\right), 40^{\circ} \mathrm{F}\left(4.4^{\circ} \mathrm{C}\right)$ and $10^{\circ} \mathrm{F}\left(-23.3^{\circ} \mathrm{C}\right)$. The course of $\lambda_{P U R}$ was determined at regular intervals and results published for two years, three years and four years of ageing. One key finding of Wilkes et al. was that the $\lambda_{P U R}$ of all test specimens increased throughout the investigation period, regardless of the $T_{a}$ the test specimens were exposed to [46-[48]. Another key finding was that specimens under a high $T_{a}$ were subject to accelerated ageing compared to specimens aged under a lower $T_{a}$ [[48]. In addition to the $T_{a}$, condensation and insulation moisture content are factors of degrading efficiency. Condensation occurs within the pores of closed-cell foam insulations as soon as temperatures drop below the dew point of water vapour, which has previously diffused into the cells $[[27,[31,[49]$. The $\lambda$ rises as a consequence of the higher conductive property of the liquid phase compared to the gaseous phase $[[9,[31]$. Studies investigating the long-term effect of high moisture levels on closed-cell foam insulations found that water vapour is absorbed over time and deteriorates the insulation properties [[9, [50]. Zhang et al. [51] conducted extensive research on factors, such as humidity and moisture content, affecting changes in $\lambda_{P U R}$. The influences of humidity, alternating high and low $T_{a}$ and atmospheric gas pressure on the $\lambda_{P U R}$ of five PUR foam samples were investigated comprehensively. Results show that moist air increases $\lambda_{P U R}$ between 10-18\% [51]. However, for some refrigeration 
appliances with embedded cold wall evaporators moisture can migrate through the foam, aggregate around the evaporator and reduce its performance in the long term, resulting in foam degradation and additional technical wear.

\subsubsection{Impact of facings on the ageing of foam insulations}

Nowadays, it is a general state of the art that rates of foam insulation degradation are significantly reduced by using facing materials. For instance, the application of metal as a gas-diffusion tight facing reduces foam insulation degradation within the lifetime of refrigerators. Plastic materials, such as high impact polystyrene (HIPS) or acrylonitrile butadiene styrene $(A B S)$ are potent barrier materials and lower gas diffusion rates of PUR. However, HIPS or ABS still allow gas diffusion to a remarkable extent so that foam ageing and the associated increase in $\lambda_{P U R}$ cannot be fully avoided. Ozkadi [52], for instance, investigated the impact of ageing on PUR systems with different facings by evaluating changes in the $\lambda_{P U R}$ after one year and three years. The $\lambda_{P U R}$ of unfaced test samples increased from $21 \mathrm{~mW} /(\mathrm{m} * K)$ to $25 \mathrm{~mW} /(\mathrm{m} * K)$ within the first year of ageing, whereas the $\lambda_{P U R}$ of fully sealed samples increased from $21 \mathrm{~mW} /(m * K)$ to $23 \mathrm{~mW} /(m * K)$ after 3 years [52]. Unlike Ozkadi, Fleurent et al. [[31] examined the barrier effectiveness of different facing materials on PUR test samples to reduce the gas diffusion phenomena and its associated change in the $\lambda_{P U R}$ over time. Test samples with casing were either covered by a bitumen/glass-fibre facing or sealed by aluminium and, alongside unfaced PUR test samples, aged at $23^{\circ} \mathrm{C}$ and $70{ }^{\circ} \mathrm{C}$ for more than a year [[31]. One important finding of Fleurent et al. was that the $\lambda_{P U R}$ of bitumen-faced samples increased from roughly $21 \mathrm{~mW} /(\mathrm{m} * \mathrm{~K})$ to $25.5 \mathrm{~mW} /(\mathrm{m} * \mathrm{~K})$ after 400 days of ageing at $70{ }^{\circ} \mathrm{C}$. This corresponded to the increase in $\lambda_{P U R}$ of the unfaced sample from $21 \mathrm{~mW} /(\mathrm{m} * \mathrm{~K})$ to $26 \mathrm{~mW} /(\mathrm{m} * \mathrm{~K})$ aged at $70{ }^{\circ} \mathrm{C}$. Another important finding was that the aluminium faced samples increased only by $1.5 \mathrm{~mW} /(\mathrm{m} * K)$ over a year under the same conditions [[31]. Recently, it has been claimed that polyethylenterephthalat $(P E T)$ holds better barrier properties than other plastic or steel casings and supports to reduce the degradation of the foam insulation performance over time (cf. WO 2019/007829, WO 2019/007030) [53],[54]. However, in-depth investigation of the influence of different facing materials on the degradation of insulation properties is an area in which more research would be beneficial.

Past studies point out that the $\lambda_{P U R}$ rises over time, proving an age-related efficiency loss of the insulation material. However, the aforementioned studies formed destructive approaches. Results are based on isolated test specimens, disconnected from the overall refrigeration system. A relationship between the ageing of test samples and changes in EC patterns of domestic cooling appliances could, thus, not be drawn. Therefore, the impact of decreasing insulation properties on the agerelated efficiency loss of household cooling appliances has never been evaluated thoroughly up to now. In contrast to previous studies, the innovation aspect of this study is to present a non-destructive testing method (Bonn method) that determines the overall insulation performance of refrigerating appliances by deriving a time constant test value $\left(\tau_{I}\right)$ which is subsequently used to calculate the heat 
transfer coefficient $\left(k_{\text {calculated }}\right)$ of the multi-layer compartment walls. The Bonn method allows the investigation of a refrigeration appliance's insulation degradation over time without influencing the properties of test objects. The method is applicable to different types of domestic refrigeration appliances, fridges, freezers, or fridge-freezer combinations alike. The degradation of different insulation materials, such as PUR and vacuum insulated panels (VIPS) including facing materials and other constructional effects can be tested and changes in performance compared to one another. This is especially important since the ageing of domestic refrigeration appliances is a topic where there is only limited research and data.

\subsection{Heat transfer through multi-layer compartment walls}

Many researchers stated that the $T_{a}$ is a dominant factor in the $E C$ of domestic refrigerators and freezers $[[9-[12,[28,[30,[38,[55]$. The reason is that up to $70 \%$ of the total thermal load comes by conduction through the compartment walls, considering empty refrigeration appliances as closed rectangular cavities [56],[57]. Throughout this paper, the term compartment refers to the enclosed space (or spaces) within a refrigerating appliance, directly accessible through an external door (or doors) [58]. The compartment may itself be divided into sub-compartments with shelves, drawers and other sections. Therewith, the compartment walls relate to the walls of the overall cabinet. Regardless of the actual insulation material, the principle of $\lambda$ applies to the heat transfer through the thermal insulation of all types of refrigeration appliances. The $\lambda$ value is generally assumed as a single constant for each material layer and component of the construction [[28]. However, the variability of the actual $\lambda$ through the rigid foam insulation depends on many factors, described in detail in the aforementioned sections. For the multi-layer compartment walls of refrigeration appliances a stationary heat transfer occurs due to temperature differences between $T_{a}$ and the internal compartment temperature $\left(T_{i}\right)$ [[50,[55]. Radiative heat exchange occurs between the evaporator and the inside cabinet walls for appliances that are switched-on [[57]-[59]. When appliances are switched-off the effect diminishes and gradually becomes insignificant, that is, as soon as no more downstream cooling effects are emanated from the evaporator. Unlike convection and conduction, the influence of the radiative heat exchange has negligible influence on the heat transfer through the multi-layer compartment walls for $T_{a}$ of conventional installation conditions, ranging from $10{ }^{\circ} \mathrm{C}$ to 43 ${ }^{\circ} \mathrm{C}[[9,[30,[50]$. Driven by the temperature difference, heat flows through the material layers of the compartment walls and would gradually cause a rise of $T_{i}$ in the event of non-operation $[[11,[38,[56]]$. Generally, the inside wall $\left(d_{x i}\right)$ is comprised of thermoplastic synthetics with different thicknesses made up by HIPS and other processed materials. The outer wall consists of consecutive layers of steel sheet, plastic strips and other material, forming the wall exterior $\left(d_{y i}\right)$ [60],[61]. Insulation materials, such as PUR rigid foam, are embedded between the inside and outside walls. PUR dominates the components of a multi-layer refrigerating appliance wall, since it is not only important for the performance, but also for appliance stability. The temperature profile through the multi-layer compartment walls is shown in Figure 1. 


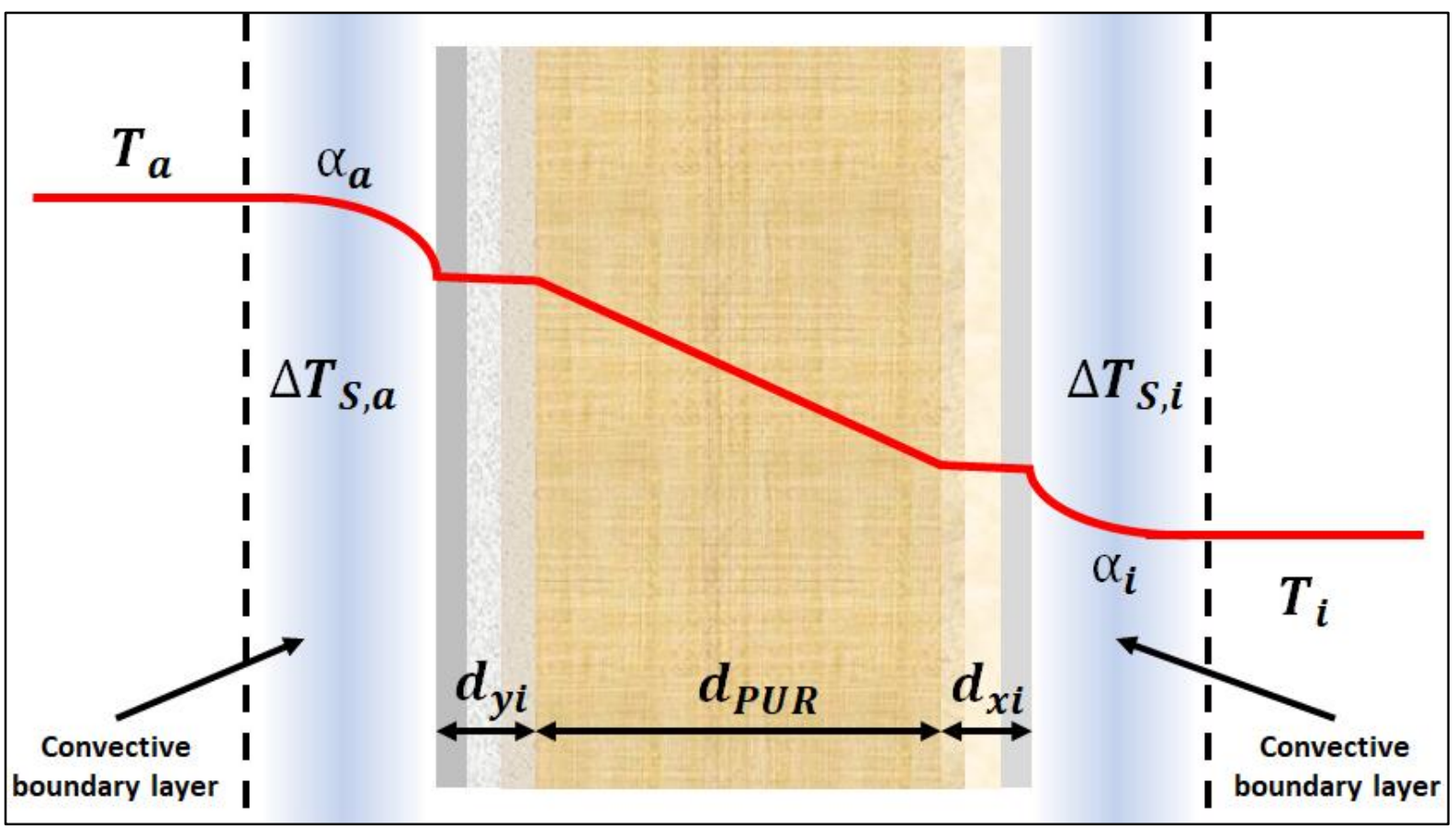

Figure 1: Temperature profile causing heat transfer through a planar refrigerator wall

Each material layer has a different $\lambda$, resulting in successive conductive heat transfers from one layer to the other. This process is described by the heat transfer coefficient $(k)$, given in $W /\left(m^{2} * K\right)$, at flat surfaces. Either the definition of a reference surface area or the cross-sectional surface area $(A)$ is required for objects of more complex geometry. This is because the heat transition at the outside wall $\left(\alpha_{a}\right)$ may vary for surface areas due to different oncoming air flow. In the following, the simplification is applied that the heat transfer through the compartment walls of household refrigeration appliances takes place on flat wall surfaces and follows a simple geometry. The calculation of the $k$ for the example given in Figure 1 is thus expressed by (1. Without this simplification, varying convective exchanges for different wall surfaces need to be taken into account, expressed by Equation in the

\section{Appendix.}

$$
\frac{1}{k}=\left(\frac{1}{\alpha_{a}}+\frac{d_{x i}}{\lambda_{x i}}+\frac{d_{P U R}}{\lambda_{P U R}}+\frac{d_{y i}}{\lambda_{y i}}+\frac{1}{\alpha_{i}}\right)
$$

While the majority of the $k$ value is made up of the effectiveness of the PUR insulation and its facing materials, other factors may influence the heat flow through the multi-layer compartment walls. These refer especially to all physical phenomena that disturb and affect the composition of the PUR insulation and its cell structure [[31]. Penetrations of the PUR insulation can be due to refrigeration piping, heaters and associated wiring, cables, drain holes and other. The actual influence of penetration sources depends on the construction of each appliance and is generally small $[[49,[50]$. 


\section{Materials and methods:}

\subsection{Preparation and analysis of sealed samples of PUR rigid foam}

To this end, moulded specimens were prepared as individual components representing the insulation foam material of refrigerators. The moulds used within the manufacturing are made of metal and faced from the inside with a manually-applied layer of aluminium to fully encase the raw test specimens of PUR rigid foam with aluminium foil after subsequent demoulding. The moulded parts were prepared from a polyol mix A with polymeric methylene diphenyl diisocyanate and cyclopentane. The polyol blend admixed with the cyclopentane (13.5 parts in 100 parts of polyol blend) was mixed with the required amount of specified isocyanate using a high-pressure mixing machine with a discharge rate of $250 \mathrm{~g} / \mathrm{s}$. The reaction mixture was injected into the previously described moulds (dimensions $2000 \times 200 \times 50 \mathrm{~mm}$ ) adjusted to a temperature of $40^{\circ} \mathrm{C}$ and demoulded after $5 \mathrm{~min}$. The degree of overpacking was $17.5 \%$, i.e. $17.5 \%$ more reaction mixture was used than was necessary to completely foam-fill the moulds. The resulting test specimens, fully covered by aluminium foil, were stored at $T_{a}$ ranging between $21^{\circ} \mathrm{C}$ and $24^{\circ} \mathrm{C}$. All test specimens comprised of closed-cell PUR only. After storing the test specimens for $24 \mathrm{~h}$ a plurality of foam cuboids (positions $10 \mathrm{~mm}$ regarding the start of the mould) of dimensions $200 \times 200 \times 50 \mathrm{~mm}$ were cut out from the centre of the specimens and each resulting foam sample entirely enveloped with aluminium foil. Sealed PUR foam samples were stored under the aforementioned temperature conditions with humidity ranging between 35-70 $\%$ with an average of about $60 \%$ relative humidity. Both cell gas composition and the $\lambda_{P U R}$ were measured at regular intervals. For this, the top and bottom sides of a part of the sealed foam samples were removed to obtain test specimens of dimensions $200 \times 200 \times 30 \mathrm{~mm}$. This way, results were obtained for samples that have been entirely covered by aluminium foil during their ageing phase. $A$ gas sample was obtained via a gas-tight syringe from the foam sample for the cell gas analysis. The foam sample was flushed with helium as an inert gas to reduce contamination from the ambient air. The gas samples ( $15 \mu \mathrm{l}$ each) were subsequently analysed by gas chromatography equipped with a thermal conductivity detector. The results are an average of two measurements. A Taurus TCA 300 DTX apparatus was used for the identification of $\lambda_{P U R}$ at an average temperature of $10^{\circ} \mathrm{C}$.

\subsection{Development of the Bonn method}

This subsection presents the development of the non-destructive Bonn method to investigate the insulation degradation intrinsic to household refrigeration appliances.

\subsubsection{Theoretical background}

The challenge was to develop a non-destructive test procedure that determines changing insulation properties of refrigeration appliances over time without deconstruction. Newton's law of cooling forms the basis of the Bonn method. It describes the temperature equalisation between an object and the ambient in the event of a temperature difference at boundary level [62]. This initial description was used to investigate the temperature rise of $T_{i}$ towards $T_{a}$ after cooling appliances were disconnected 
from a power supply. Following Newton's law of cooling, the temperature rise is characterised by an exponential increase of $T_{i}$ towards a boundary value, expressed by $T_{a}$ [62],[63]. The time dependence of this temperature rise is characterised by an exponential function and is independent of $T_{i}$ and $T_{a}$. Assuming that other heat flows through the door gaskets or condensation drain holes are omitted, the heat flow is mostly influenced by the insulation properties of the multi-layered compartment walls $[[9,[31,[49,[50]$. Since the temperature rise is initiated after appliances were switched-off, radiative heat exchange emanated from the evaporator on the inside compartment walls can be neglected. This also applies to the radiative heat exchange of the $T_{a}$ on the PUR foam insulation at conventional installation conditions, outlined in the aforementioned sections. The test method can be applied to refrigeration appliances without the need for their deconstruction. When interpreting the ageing of PUR as changing heat flow through the insulation material over time, the application of heat flow meters to determine the degradation may offer an alternative approach. However, domestic refrigeration appliances have a complex geometry with foam insulations and facings distributed unevenly among the compartment walls and the door (or doors). The effort to measure the heat transfer through various wall surfaces of the same appliance in order to calculate a uniform value determining the overall insulation performance would be large and the associated value rather imprecise. The IEC 62552-2 (Annex C) [64] reports a temperature rise test for refrigerating appliances with one or more three-star or four-star compartments. The objective is to determine the time necessary for the temperature of test packages (M-packages) to rise from $-18{ }^{\circ} \mathrm{C}$ to $-9{ }^{\circ} \mathrm{C}$ after switch-off. However, this test is only applicable to refrigerating appliances with at least one freezer compartment, each compartment needs to be loaded with M-packages and measuring points recording the temperature rise are not specifically defined [64]. Due to additional limitations, this test is not applicable for detailed investigation of refrigerating appliance's insulation degradation over time.

\subsubsection{Methodological approach}

The theoretical approach was first applied to a sample refrigerator to understand its practical application. Figure 2 presents the corresponding temperature profiles throughout the Bonn method. 


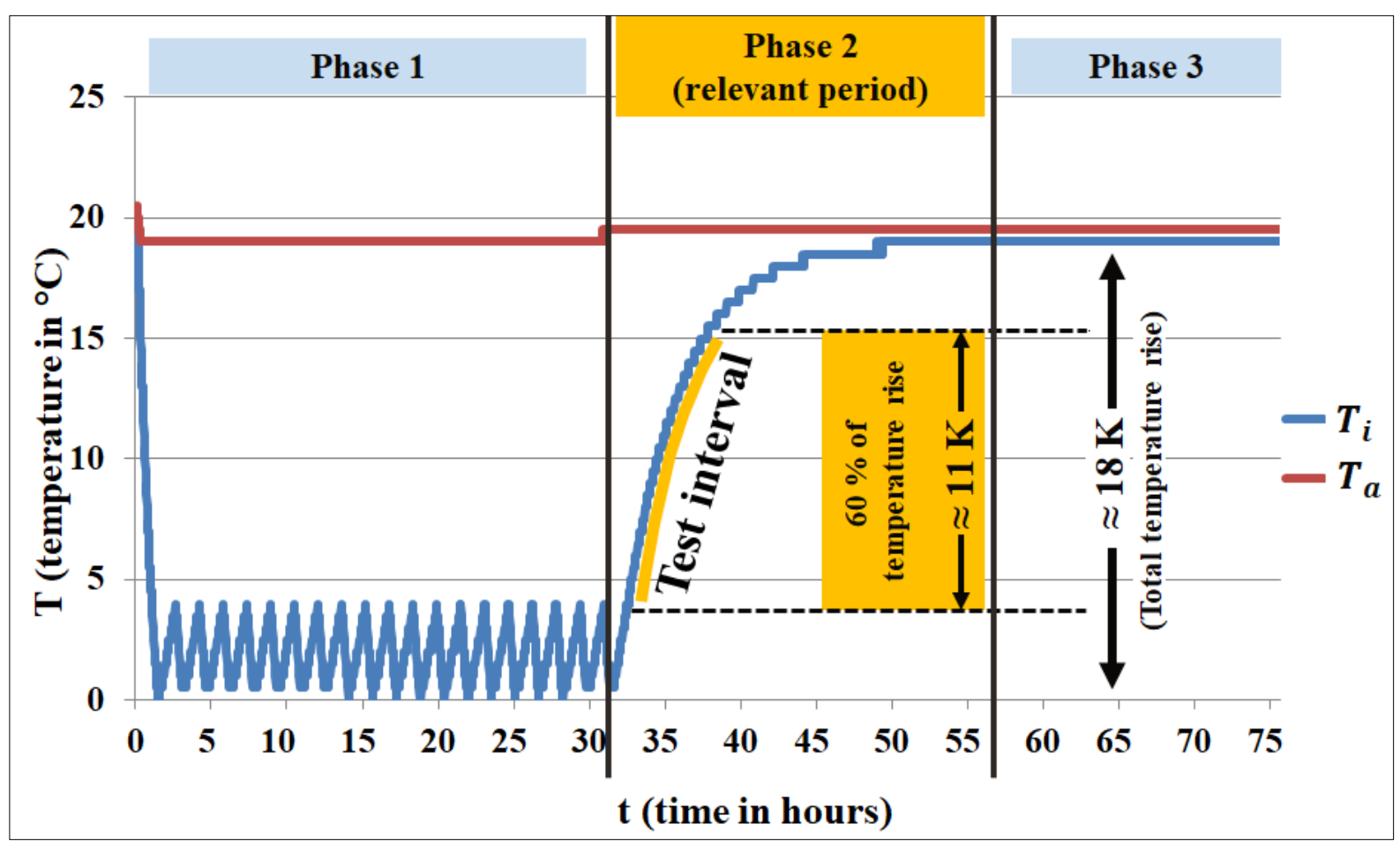

Figure 2: Temperature profile of a sample appliance throughout the application of the Bonn method

Temperature data was measured every minute but is presented in hours to improve the readability of Figure 2 and the related figures (Figure 3a1, Figure 3b2). The application was conducted under a controlled $T_{a}$ of $20^{\circ} \mathrm{C} \pm 1$ Kelvin $(K)$. Lascar electronics EasyLog EL-USB-1 temperature loggers were used as sensors recording air temperature data $\left(T_{a}\right.$ and $\left.T_{i}\right)$. Chosen temperature sensors operate at $0.5{ }^{\circ} \mathrm{C}$ resolution within an operating temperature range from $-35^{\circ} \mathrm{C}$ to $80{ }^{\circ} \mathrm{C}$. VOLTCRAFT ENERGY-LOGGER 4000, power and energy meters with a resolution of 0.1 watts were additionally used to display the power flow throughout the application. First, the overall course of $T_{i}$ was divided into three subsequent phases. The first section marks the initial phase, the second the relevant measurement period and the third the phasing-out period. The initial phase showed $T_{i}$ at steady-state conditions reflecting the power on-off cycles of the compressor. The sample test device was disconnected from the power supply when the temperature difference between $T_{i}$ and $T_{a}$ was at a maximum. The second phase contains the approximation of $T_{i}$ towards $T_{a}$ and is, thus, referred to as the relevant period. This section started after disconnecting the appliance from the power supply. The following phasing-out period reflects the completed temperature equalisation of $T_{i}$ towards $T_{a}$. Figure 2 shows that the total rise in temperature amounted to approximately $18 \mathrm{~K}$. Second, the test interval of the temperature rise (roughly $11 \mathrm{~K}$ ) was determined and used for the calculation of the decay constant test value $\left(\tau_{I}\right)$, measured in $(1 / t)$. An amount of $60 \%$ of the total temperature rise was used to generate the test interval, disregarding $20 \%$ at the beginning and the end of the relevant period, respectively. This is because uncertainties influenced both ends of the temperature rise. Initial values would have been distorted by downstream effects after the sample appliance was disconnected from the power supply, e.g. by downstream cooling effects of the evaporator or pressure equalisation of the 
refrigeration system. Downstream cooling effects of the evaporator were verified by measuring the surface temperatures of plate evaporators using sheathed thermocouple models with a naked junction between compressor on and off cycles. Resulting temperature profiles of evaporator surfaces indicated that downstream cooling effects only last a few minutes. Additionally, the limited resolution of the temperature sensors employed would have resulted in a large relative uncertainty of $T_{i}$ and $T_{a}$ at the end of the temperature rise. The remaining temperature rise provides the test interval. Due to the temperature measuring accuracy of used loggers $\left( \pm 0.5^{\circ} \mathrm{C}\right)$, all data points of $T_{i}$ recorded within the test interval were smoothed. Subsequent to the derivation of the test interval, the $\tau_{I}$ determining the insulation quality of the sample appliance at the time of test application could be calculated. Newton's law of cooling was used to calculate $\tau_{I}$, since the test interval reflects a distinct section in the approximation of $T_{i}$ towards $T_{a}$. Its basic formula is given by Equation (2).

$$
T_{i}(t)=\left(T_{i}(0)-T_{a}(0)\right) * e^{-\tau_{I}(t) * t}+T_{a}(t)
$$

$\tau_{I}$ presents the decay constant and, for data measured at every minute, is given in $\min ^{-1} . T_{i}(t)$ and $T_{a}(t)$ give the temperature courses at every point in time throughout the test interval, whereas $T_{i}(0)$ and $T_{a}(0)$ resemble the initial values of $T_{i}$ and $T_{a}$ at the start of the test interval, respectively. Equation (2) was transformed to estimate the slope of the temperature rise at every recorded time instance ( $t$ in $\mathrm{min}$ ) within the test interval, shown by Equation (3).

$$
\tau_{I}(t)=1 / t * \ln \frac{T_{i}(0)-T_{a}(0)}{T_{i}(t)-T_{a}(t)}
$$

Based on Equation (3), $\tau_{I}(t)$ describes the gradient of all $T_{i}$ data points measured within the test interval. Referring to Figure 2, Figure 3a1 presents the overall course of $\tau_{I}(t)$.

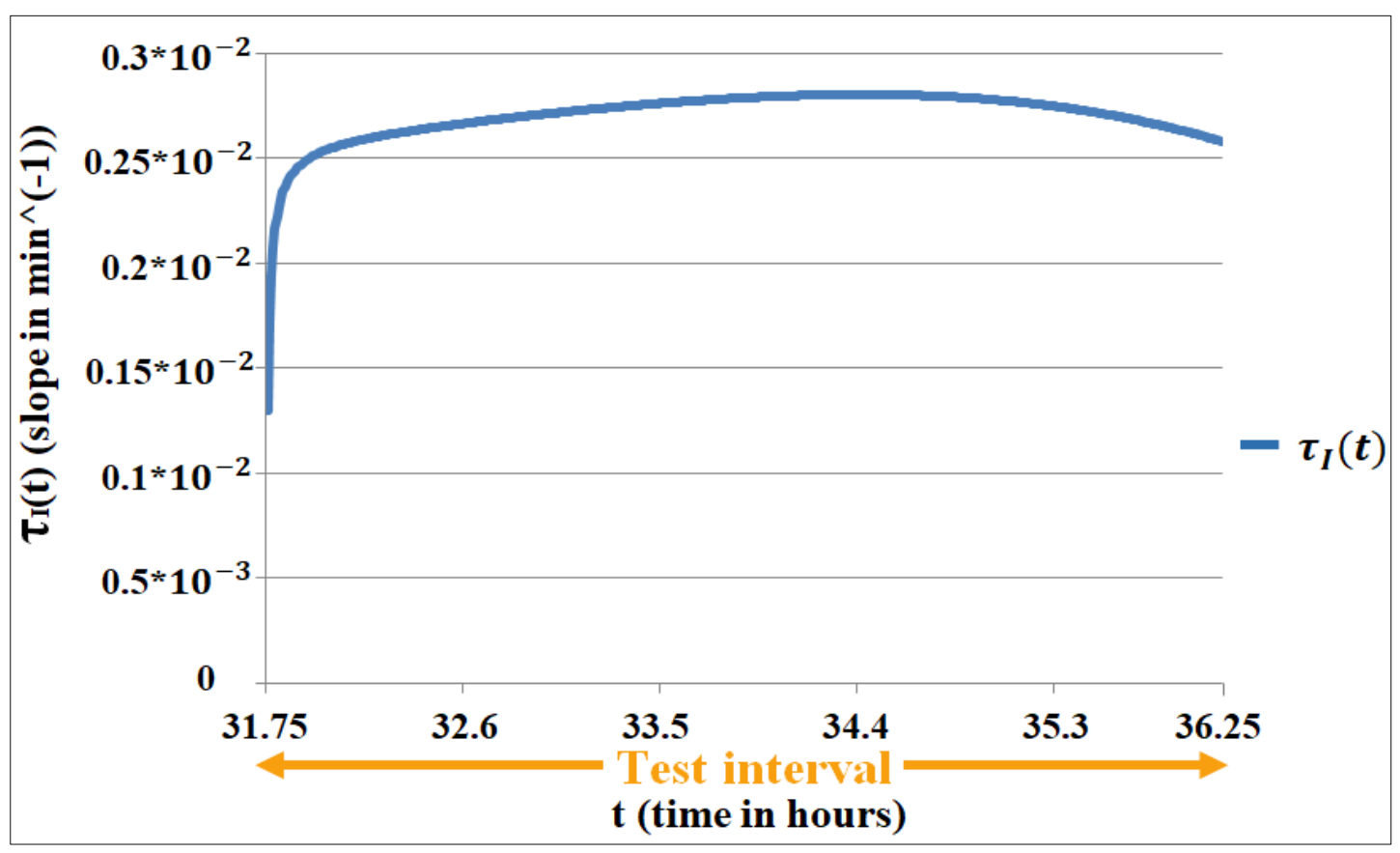

Figure 3a: Course of $\tau_{I}(t)$ for a sample appliance 


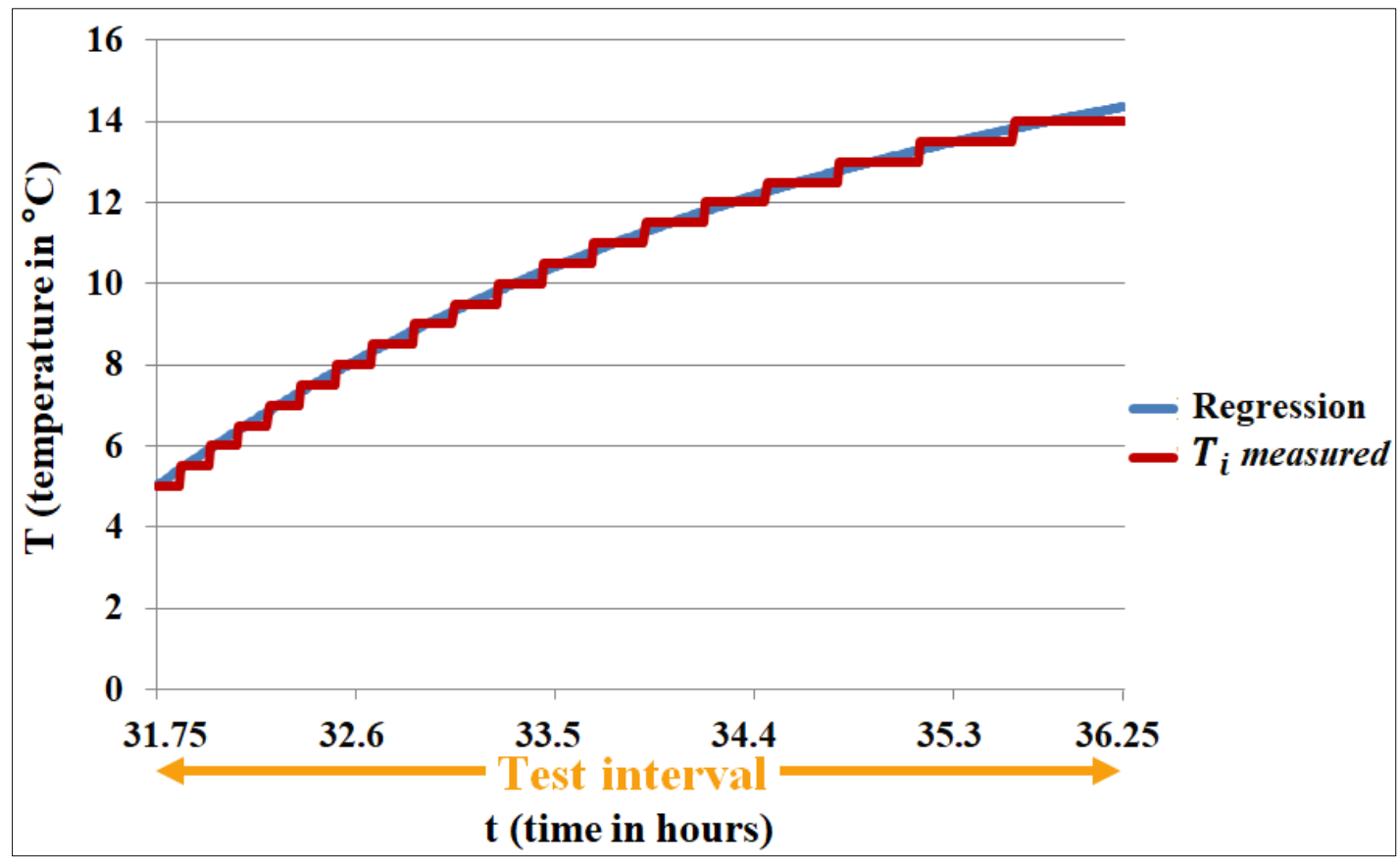

Figure $3 b$ : Regression with $\tau_{I}\left(\max =\tau_{I}(t)\right)$ for a sample appliance

$\tau_{I}$ is located at the maximum of all $\tau_{I}(t)$ within the test interval, determining the deteriorating state of the thermal insulation. Regarding Figure $3 a 1, \tau_{I}$ is at approximately $0.28^{*} 10^{-2} \mathrm{~min}^{-1}$. The initially steep increase of $\tau_{I}(t)$ is due to the fact that $T_{i}(0)$ and $T_{i}(t)$ are equal at the first measuring point of the test interval. Figure $3 \mathrm{~b} 2$ further shows that the $T_{i}$ measured within the test interval $\left(T_{i}\right.$ measured) of the sample appliance is best resembled by a regression using the maximum of all $\tau_{I}\left(0.28^{*} 10^{-2}\right.$ $\mathrm{min}^{-1}$ ) as a constant gradient. The compliance is indicated by a high-quality adaption rate of the regression to $T_{i}$ measured (Figure 3b2), given by a coefficient of determination $\left(R^{2}\right)$ larger than 0.99 . Therefore, $\tau_{I}$ is defined as the test value of the Bonn method, determining the overall insulation performance of refrigerating appliances through a defined temperature rise in a compartment under specified conditions. Since PUR dominates the wall components of domestic refrigerating appliances, a degradation of the insulation dominates changes in $\tau_{I}$ over time. One potential systematic uncertainty of measurement is that not only the direct conductivity of heat through the multi-layer walls is included in $\tau_{I}$, but also other heat dissipations. To prevent another systematic uncertainty of the Bonn method, test parameters (resolution of time and temperature) to record $T_{i}$ and $T_{a}$ need to be consistent for all experiments of a test series.

\subsubsection{Materials}

The Bonn method is applied to a range of 15 different domestic refrigeration appliances, including refrigerators, freezers and fridge-freezer combinations. The composition of appliances reflects the German market composition. Consequently, appliances of different construction, price ranges, storage volume and varying insulation material (VIPS and PUR) are under investigation. All appliances were either acquired new or provided directly by the manufacturers. However, in this 
contribution, the methodological approach of the Bonn method was applied to two inventory appliances, in the following referred to as $A$ and $B$. In contrast to new appliances, $A$ and $B$ were chosen due to their age. In contrast to destructive tests investigating the insulation properties over time, the impact of non-destructive insulation improvements on $\tau_{I}$ and associated changes in $E C$ could be simulated. Thus, the impact of the insulation degradation on refrigeration appliance's $E C$ over time could be investigated while holding all other ageing impact factors constant. The characteristics of test appliances A and B are specified in Table 1.

Table 1: Characteristics of test appliances A and B

\begin{tabular}{l|ll}
\hline Specifications & Appliance A & Appliance B \\
\hline Type & $\begin{array}{l}\text { Refrigerator, } \\
\text { Built-in, } \\
\text { No freezer compartment }\end{array}$ & $\begin{array}{l}\text { Refrigerator, } \\
\text { Free-standing, } \\
\text { One four-star }{ }^{1} \text { compartment }\end{array}$ \\
\hline Age & 9 years & 33 years \\
\hline Storage volume & 312 litres & 145 litres \\
\hline Power rating (W) & 90 & 110 \\
\hline Cooling & Dynamic & Static \\
\hline
\end{tabular}

Appliances $A$ and $B$ operated on the lowest adjustable temperature level throughout all experiments. The interior equipment of $A$ and $B$, such as shelves and drawers, was left in place. Both appliances remained unloaded throughout the test application. To receive detailed temperature profiles, both, $T_{a}$ and $T_{i}$ were measured every minute throughout test applications. The aforementioned temperature sensors used for the practical application on the sample appliance were also used for all subsequent temperature measurements concerning appliances $A$ and B. One sensor was used per compartment. Temperature sensors were placed on determined spots within appliances $A$ and $B$, located at the geometric centre of each appliance, which is precisely the centre point of the centre shelf within the appliance's cabinet. In the case of fridge-freezer combinations two temperature sensors would be used, located in each compartment as previously described. A detailed positioning of temperature sensors for appliances $A$ and $B$ is given by

\footnotetext{
${ }^{1}$ Refrigerating appliance defined according to IEC 62552-1 (2014).
} 


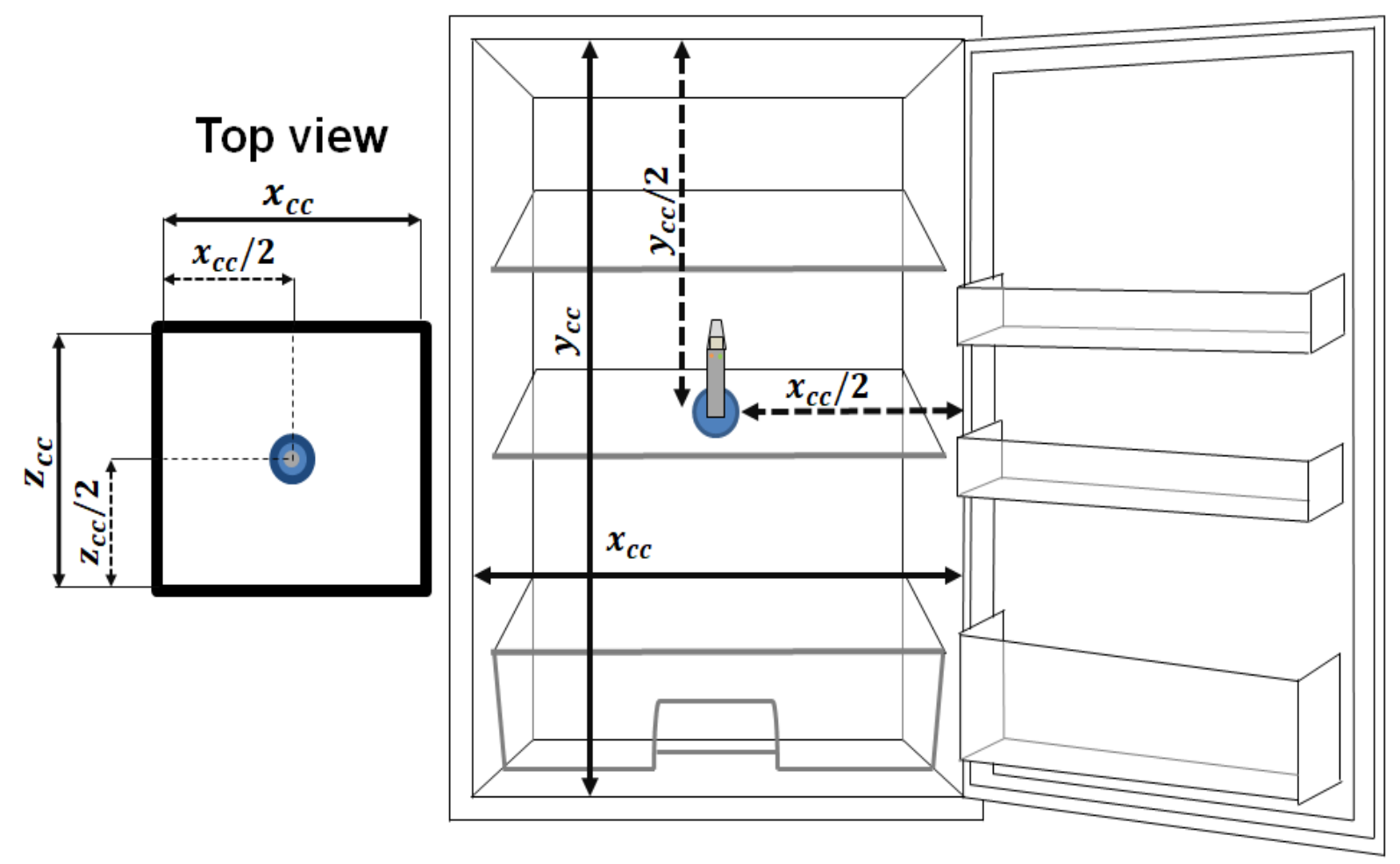

Figure in the

Appendix. For reasons of simplification the four-star freezer compartment of appliance B is disregarded
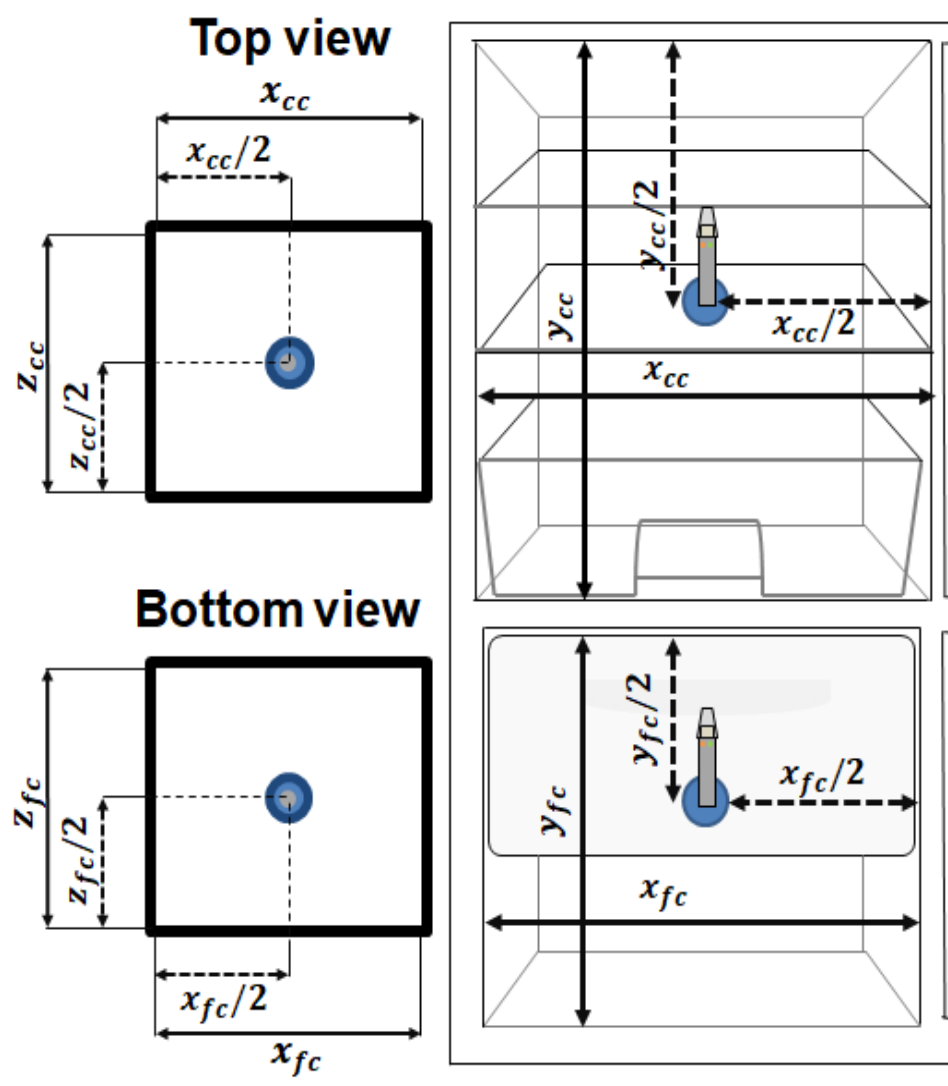

the following.

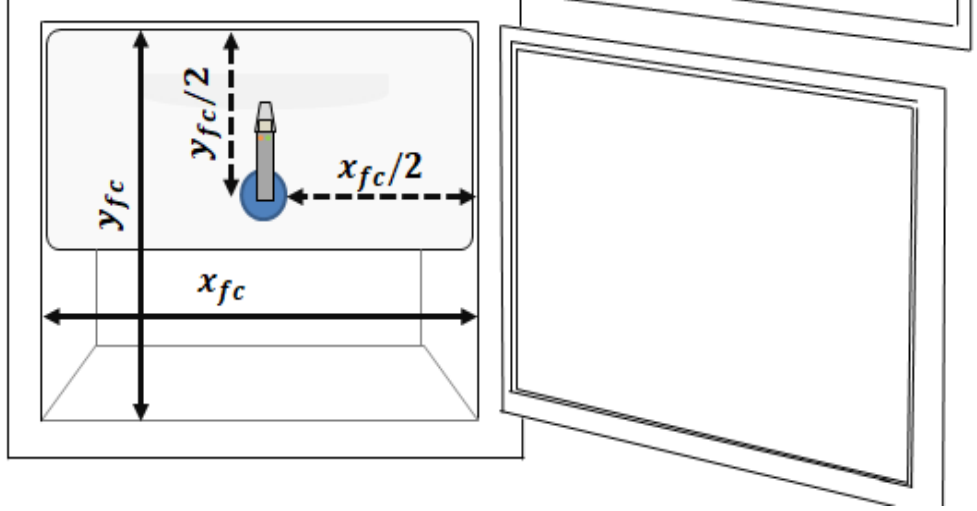

Figure indicates the temperature measuring positions for more complex appliances, such as fridge- 
freezer combinations, not further specified in this contribution. For appliances A and B, Ramoflex kneading paste 832 (water repellent and temperature resistant) was used to seal the condensate drain holes and OVP lashing straps were used to press the door-sealing on the sill height at every test run. Previously mentioned VOLTCRAFT ENERGY-LOGGER 4000 was plugged between the power supply and socket of appliances $A$ and $B$ to observe the course of the compressor on-off mode and to measure the $E C$, respectively. Both test appliances were placed in an ambient with constant $T_{a}$ of 20 ${ }^{\circ} \mathrm{C} \pm 1 \mathrm{~K}$ for the implementation of the Bonn method. The $E C$ measurements were carried out under laboratory conditions with $T_{a}$ of approximately $25^{\circ} \mathrm{C}$, following DIN EN 62552:2013 [65].

\subsubsection{Influence of the $T_{a}$ on the Bonn method}

The Bonn method was first applied to A and B in a series of successive tests with different $T_{a}$ conditions to evaluate the dependence of $\tau_{I}$ on the $T_{a}$. Both, $T_{a}$ and $T_{i}$ were recorded every minute. A total of six test runs was carried out on appliance $A$, three at an $T_{a}$ of $19-21^{\circ} \mathrm{C}$ and three around $31^{\circ} \mathrm{C}$, respectively. Three test runs were conducted for appliance $\mathrm{B}$ at the same $T_{a}$ settings. Figure 41 shows the distribution of $\tau_{I}$ for $\mathrm{A}$ and $\mathrm{B}$ at tests with different $T_{a}$ conditions.

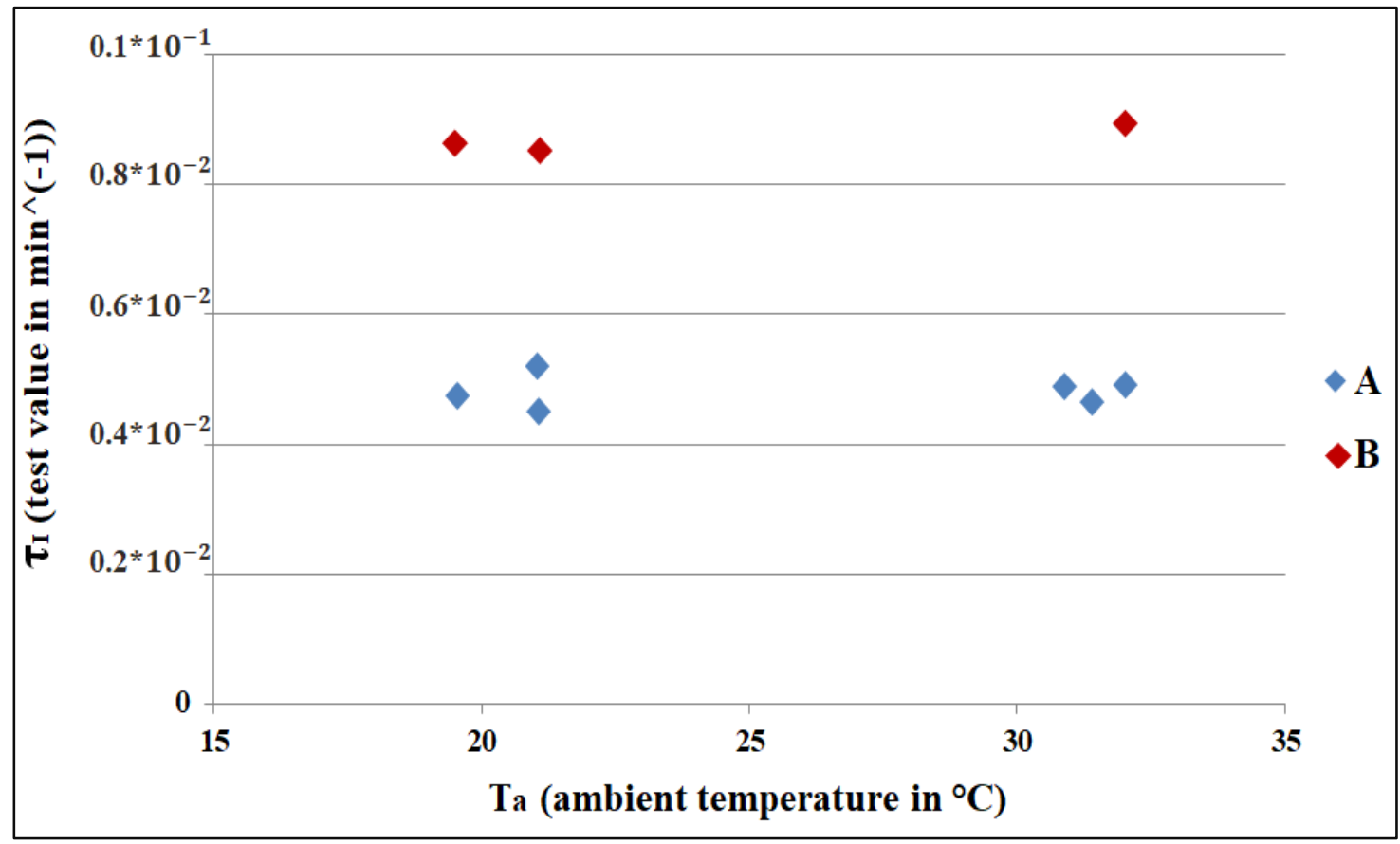

Figure 4: $\tau_{I}$ for various $T_{a}$

Regarding device A, $\tau_{I}$ remained stable at a mean value of $0.49^{*} 10^{-2} \mathrm{~min}^{-1}$ despite a variation of $T_{a}$ of more than $10 \mathrm{~K}$ between test repetitions. Device B remained equally constant at a mean value of $0.87^{*} 10^{-2} \mathrm{~min}^{-1}$. Percentage standard deviations of $A$ and $B$ were at $4.6 \%$ and $2 \%$, respectively. This indicates an independence of $\tau_{I}$ from $T_{a}$ and a high degree of reproducibility despite differences in $T_{a}$ between test repetitions. 


\subsubsection{Verification of the Bonn method}

Conversely to an insulation degradation, an improvement of the insulation was simulated and its influence on $\tau_{I}$ and the $E C$ measured for appliances $A$ and $B$, respectively. Since $P U R$ dominates the wall components of domestic refrigerating appliances, the feasibility of the Bonn method could be investigated by varying the insulation properties of both appliances. For this, two additional casings per test appliance, each called $E 1$ and $E 2$, were designed and subsequently applied to the surfaces of $A$ and $B$ to simulate an insulation improvement. $E 1$ and $E 2$ were constructed of single panels of closed-cell extruded polystyrene foam, commonly referred to as styrofoam or XPS. URSA XPS D panels were used for the construction of E1 and E2. Each panel of XPS used for construction of E1 and E2 had a material thickness (d) of $20 \mathrm{~mm}$ and, according to manufacturer product information, a $\lambda$ of $0.031 \mathrm{~W} /(m * K)$. The first casing (E1) for each test appliance was specifically designed to fit on the outer surface of its corresponding appliance $A$ or $B$, whereas the second casing (E2) was designed to fit tightly onto $E 1$. Both appliances, $A$ and $B$, had conventional wire tube condensers at the back surfaces. $E 1$ and $E 2$ omitted the bottom and back surfaces of $A$ and $B$, covering four out of six appliance surface areas. Therefore, neither the application of $E 1$, nor the subsequent application of $E 2$ onto $E 1$ impacted on the ability of the condensers to reject heat. The $E C$ of $A$ and $B$ were measured initially. Afterwards, the Bonn method was applied to calculate $\tau_{I}$ without insulation improvement. This state refers to the base case in the following. Given the initial values, E1 and E2 were applied successively. Influences of simulated insulation improvements on $\tau_{I}$ and the $E C$ could, thus, be examined for both test appliances and relationships drawn. The process was repeated three times for each scenario of simulated insulation improvement. The application of additional casings per test appliance (E1 and E2) is not an integral element of the Bonn method, but served the sole purpose to simulate improvements in insulation performance and show resulting changes to $\tau_{I}$ and the $E C$.

\section{Results:}

\subsection{Ageing of sealed samples of PUR rigid foam}

Figure $5 \mathrm{a} 1$ and Figure $5 \mathrm{~b} 2$ refer to the findings regarding the investigation of the stand-alone ageing of moulded parts of PUR rigid foam. Figure 5a1 shows the cell gas analysis of sealed PUR rigid foam samples up to 337 days of storage, while Figure $5 \mathrm{~b} 2$ presents the corresponding $\lambda_{P U R}$ measurements. 


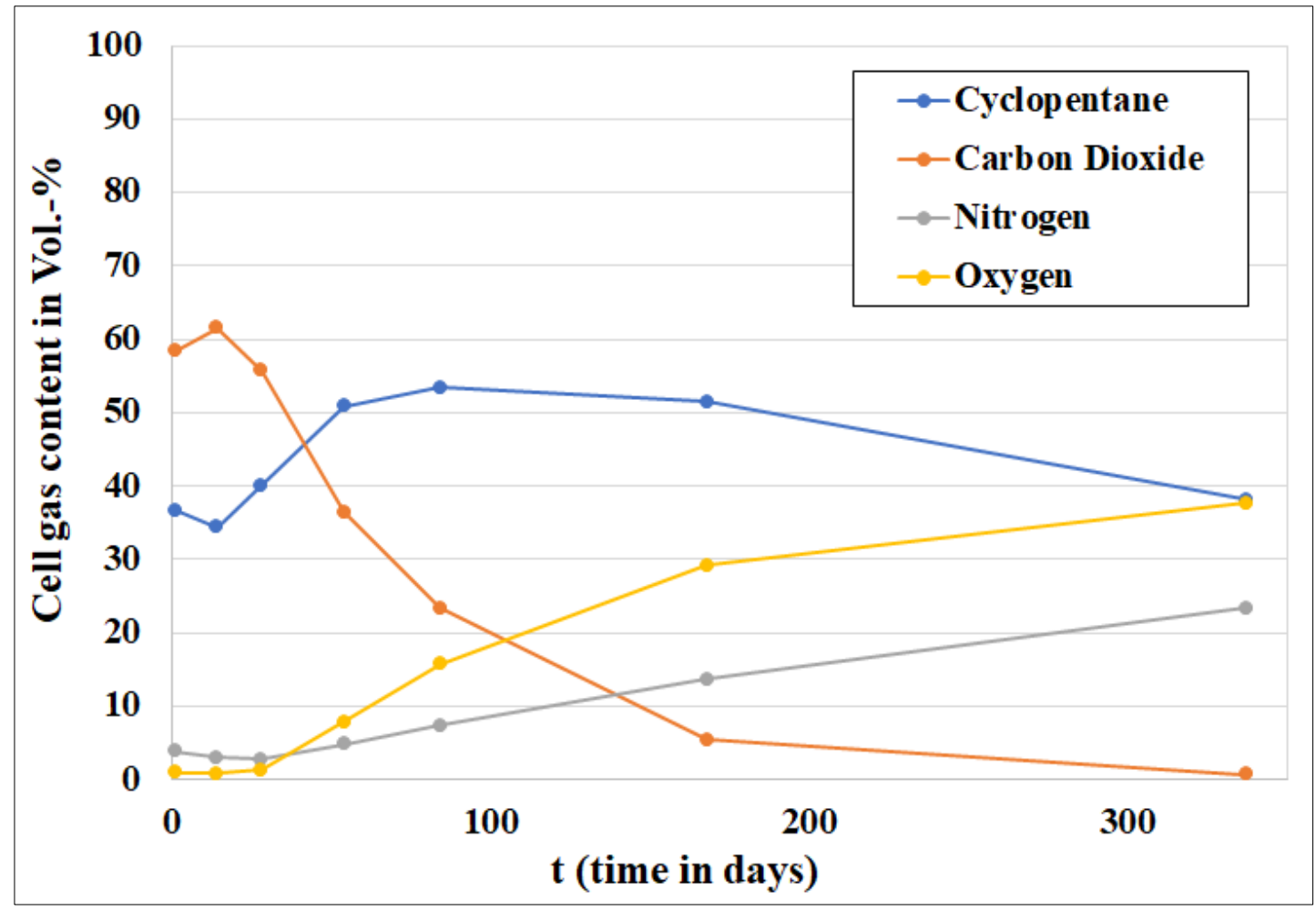

Figure 5a: Changes in cell gas composition over time

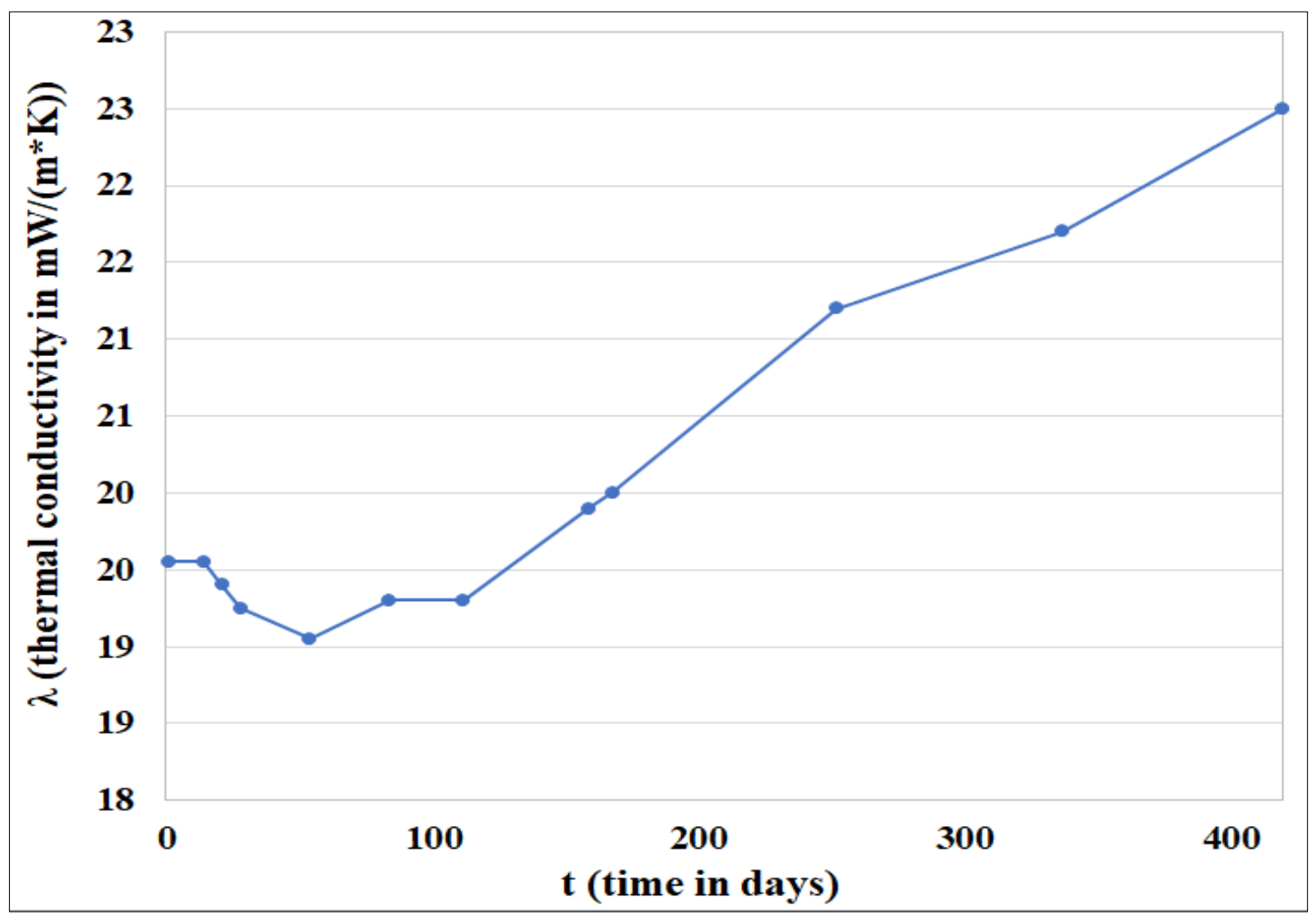

Figure 5b: Thermal conductivity of PUR rigid foam over time

Figure 5a1 indicates that the cell gas composition of the sealed samples changes significantly within the first year of investigation. Carbon dioxide initially made up more than $60 \%$ of the cell gas volume but started to diffuse out of the test specimens at an early stage. Measurements showed that its gas 
content declined exponentially throughout the test period and progressed towards zero. In contrast to carbon dioxide, the cell gas contents of nitrogen and oxygen increased from approximately $4 \%$ and 1 $\%$ to $23 \%$ and $39 \%$, respectively. Changes in gas composition represent the diffusion of cell gases (carbon dioxide and cyclopentane) and their replacement by ambient air (nitrogen and oxygen). Correspondingly, results indicate an increase in moisture by $15 \%$. Figure $5 \mathrm{~b} 2$ shows the corresponding development in $\lambda_{P U R}$ of the sealed samples, indicating an increase by roughly $15 \%$ within the test period. All sealed samples were encased by aluminium foil during their ageing and the closed-cell content was carefully tested for every specimen so that only foams with nearly $100 \%$ closed-cell content have been evaluated within the investigations.

\subsection{Relationship between $\tau_{I}$ and EC}

Figure 61 and Figure 71 show results regarding the relationship between $\tau_{I}$ and $E C$ in the case of artificial insulation improvement, referring to the subsequent application of $E 1$ and $E 2$ to $A$ and $B$ described in the aforementioned sections. The $T_{a}$ for each test concerning Figure 61 and Figure 71 are listed in

Table ii, given in the

\section{Appendix.}

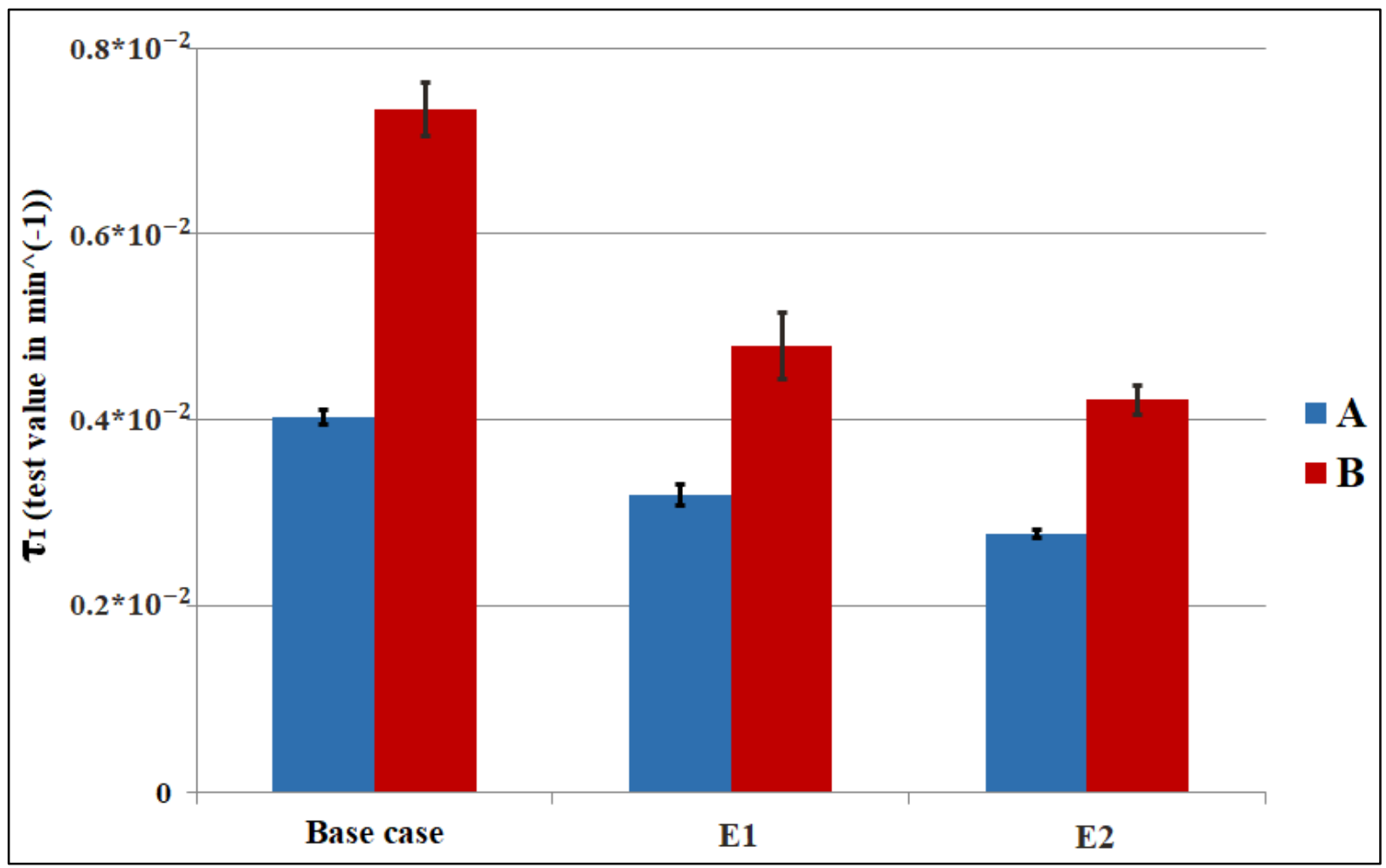

Figure 6: $\tau_{I}$ values of test appliances A and B 


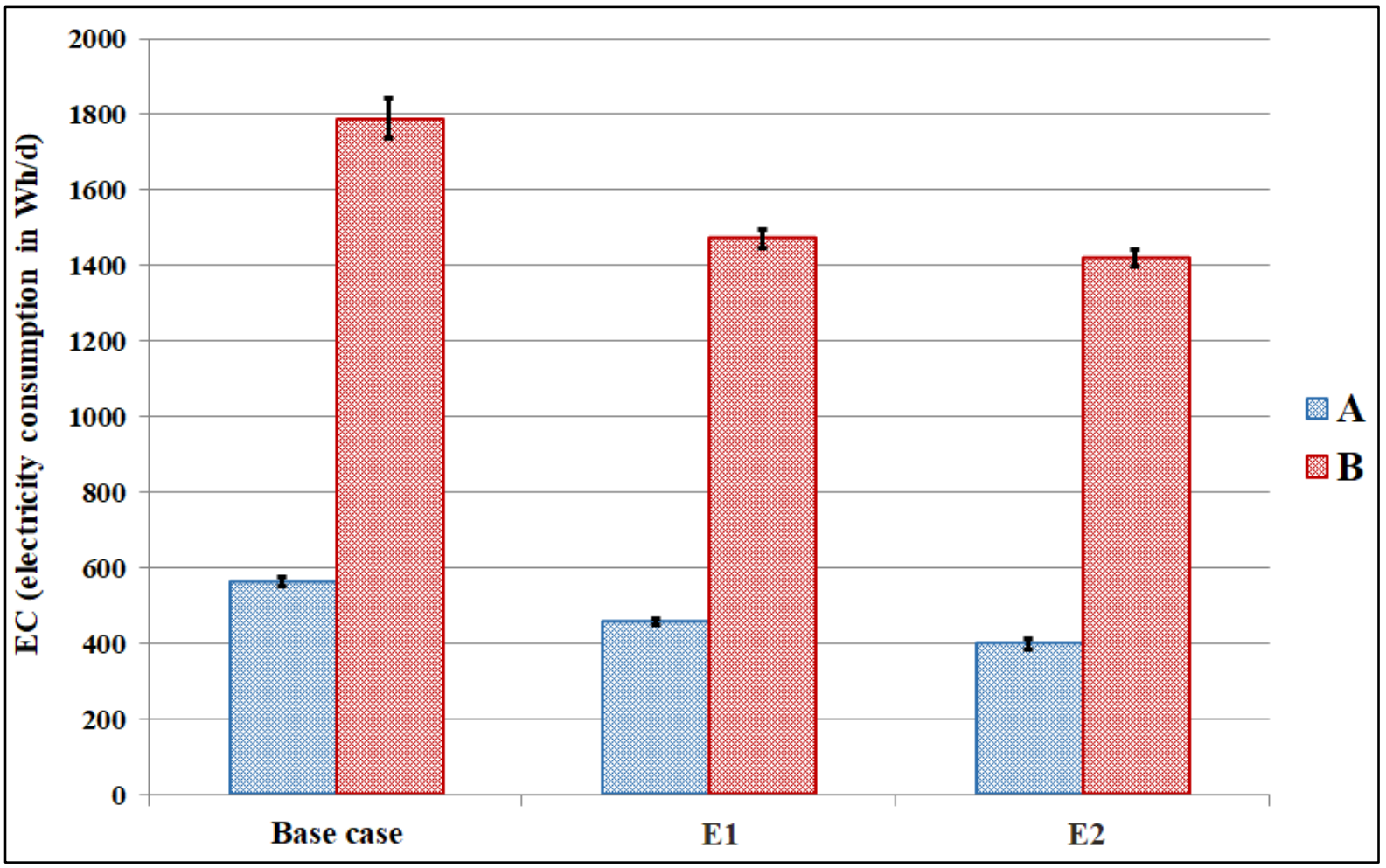

Figure 7: $E C$ of test appliances $A$ and $B$

Figure 61 indicates that $\tau_{I}$ decreases with the application of additional layers of insulation, corresponding to the decrease in $E C$ for $A$ and $B$, given by Figure 71. Regarding test appliance $A$, the mean $\tau_{I}$ of three successive measurements per scenario decreases by roughly $31 \%$, whereas the mean $\tau_{I}$ of appliance B decreases more pronouncedly by $43 \%$. Figure 71 shows that the EC measurements of appliances $\mathrm{A}$ and $\mathrm{B}$ follow almost congruent courses with the associated $\tau_{I}$ values. The mean $E C$ of appliance $A$ decreased by $29 \%$, whereas the mean $E C$ of device $B$ decreased by 21 $\%$ from the base case scenario up to $E 2$. Changes in $\tau_{I}$ and $E C$ were almost proportional regarding appliance $\mathrm{A}$, whereas a decrease in $\tau_{I}$ led to a lower than proportional reduction in $E C$ regarding appliance B. Since A and B are different refrigerator models (Table 1), their results cannot be compared directly with each other. Therefore, preliminary results were further evaluated to investigate whether a correlation between changes in $\tau_{I}$ and the EC exists. Figure 81 shows the correlation between $\tau_{I}$ and the $E C$ in the case of simulated insulation improvement for $\mathrm{A}$ and $\mathrm{B}$, respectively. 


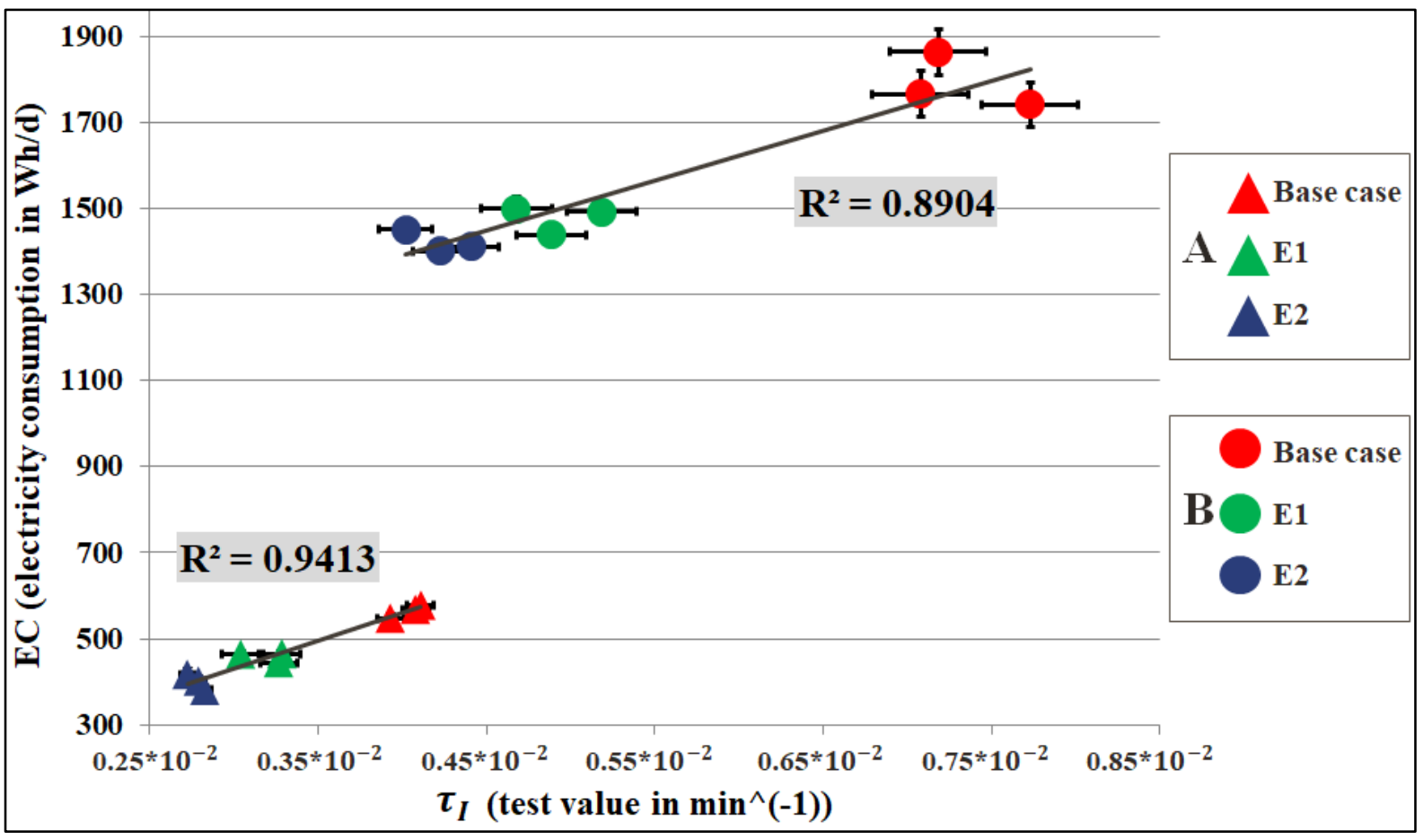

Figure 8: Correlation between $\tau_{I}$ and $E C$ in the case of simulated insulation improvement

Referring to appliance $\mathrm{A}$, standard deviations of both $\tau_{I}$ and $E C$ were small in all three scenarios, whereas the standard deviation of appliance $B$ was large in the base case scenario. This variation of $\tau_{I}$ was also given in 6 Figure 61. Figure 81 further presents the linear correlation of $A$ and $B$ for the simulated insulation improvement. The corresponding $R^{2}$ of both test appliances shows a distinct correlation between $\tau_{I}$ and the $E C$. Contrary to the simulated insulation improvement, the age-related degradation of a domestic refrigerator's insulation is, therefore, pointed out by an increase of $\tau_{I}$ over time, corresponding to a rising $E C$.

Preliminary results concerning the ageing of detached PUR rigid foam samples and $\tau_{I}$ point out important findings. Both approaches emphasize the ageing of the thermal insulation based on increasing heat flow over time. However, the destructive method determines the increase in $\lambda_{P U R}$ based on sealed PUR samples, whereas $\tau_{I}$ reflects the $k$ through the multi-layer refrigerator compartment walls. Additionally, preliminary results concerning the Bonn method indicate the influence of cover layers and facings on the age-related efficiency loss.

\subsection{Relationship between $\tau_{I}$ and $k$}

The heat flow through the multi-layer compartment walls $(\dot{Q})$ was connected to $\tau_{I}$ to indicate the insulation degradation over time. Equation (4) served as a starting point and $\dot{Q}$ as a link to relate $\tau_{I}$ with $k$. Equation (4) gives the heat flow of Newton's law of cooling for an unspecified cross-sectional surface area $(A)$, whereas Equation (5) gives the heat flow into a heat sink from an ambient at a constant temperature with a given isochoric heat capacity $\left(C_{V}\right)$. 


$$
\begin{aligned}
& \dot{Q}=A * k *\left(T_{a}(t)-T_{i}(t)\right) \\
& \dot{Q}=C_{V} * \frac{d\left(T_{i}(t)\right)}{d t}
\end{aligned}
$$

$C_{V}$ relates to the isochoric heat capacity of all compartment wall built-in material masses, such as PUR rigid foam, bulk and tech plastics. $C_{V}$ is formally described by Equation $C V=\sum_{i} c_{v} * m_{v}$.

$$
C_{V}=\sum_{i} c_{v} * m_{v}
$$

Inserting Equation (5) into Equation (4) results in the physical relationship between $\tau_{I}$ and $k$, presented by Equation (7).

$$
C_{V} * \frac{d T(t)}{d t}=A * k *\left(T_{a}(t)-T_{i}(t)\right)
$$

Converting Equation (7) and integrating over time results in Equation (8).

$$
\ln \frac{T_{i}(0)-T_{a}(0)}{T_{i}(t)-T_{a}(t)}=\frac{A * k}{C_{V}} * t
$$

Equation

(8) resembles a modified form of Newton's law of cooling for the calculation of $\tau_{I}(t)$, previously indicating the gradient of all data points of $T_{i}$ within the test interval, expressed by Equation (3). The physical relationship between $\tau_{I}$ and $k$ can, thus, be simplified as described by Equation (9).

$$
\tau_{I}=\frac{A * k}{C_{V}}
$$

Having established the physical relationship between $\tau_{I}$ and $k$, the heat flow through the multi-layer compartment walls of refrigeration appliances can be calculated. The $k$ was calculated based on the predetermined physical relationship between $\tau_{I}$ and $k$, therefore, it is referred to as $k_{\text {calculated }}$ in the following. A detailed list of materials giving comprehensive information on processed material input was provided by a European manufacturer of domestic refrigeration appliances. Alternatively, some open-source data is available which can be used to assess the material input of the compartment and calculate the associated $k_{\text {calculated }}$ [[58],[60]]. The manufacturer information was used in this paper to estimate the $d_{x i}, d_{y i}$ and $\lambda$ of different materials processed in the multi-layer compartment walls of $\mathrm{A}$ and $\mathrm{B}$. Preliminary results of changes in $\tau_{I}$ for appliances $\mathrm{A}$ and $\mathrm{B}$ with simulated insulation improvement were used to calculate the corresponding $k$ for the different insulation scenarios. 


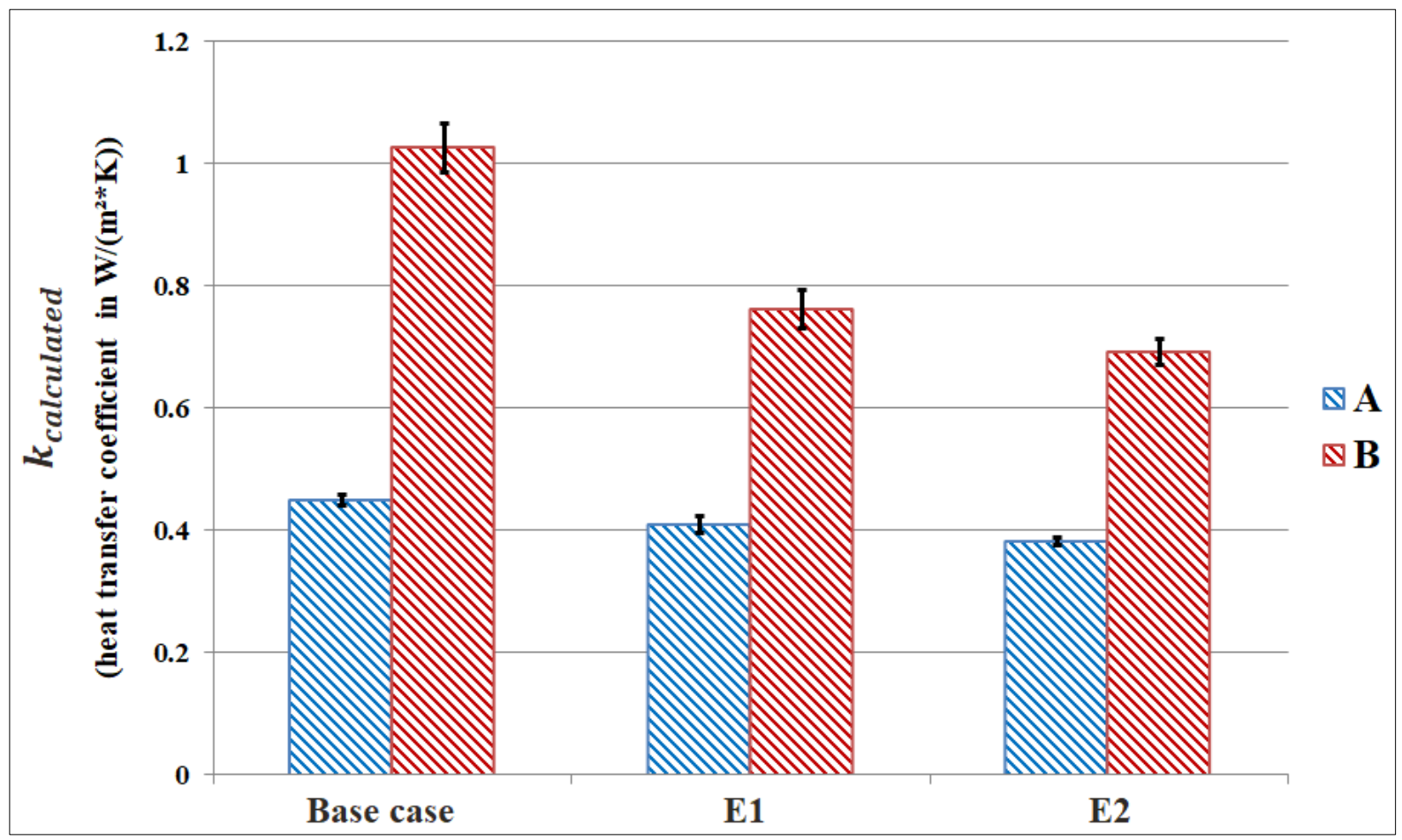

Figure 9 presents the $k_{\text {calculated }}$ regarding simulated insulation improvement for $\mathrm{A}$ and $\mathrm{B}$, respectively.

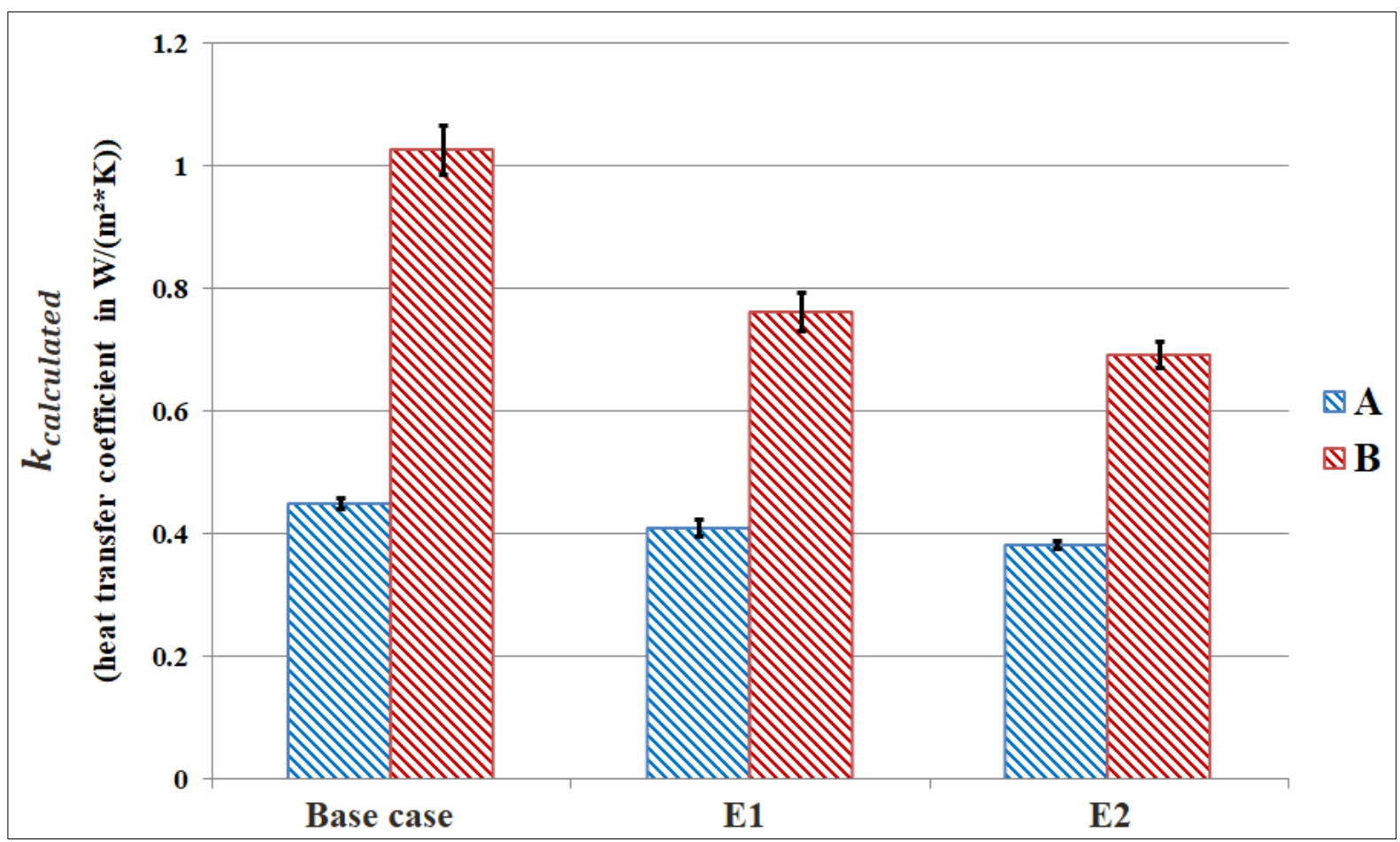

Figure 9: Mean value and standard deviation of $\boldsymbol{k}_{\text {calculated }}$ for appliances A and B 


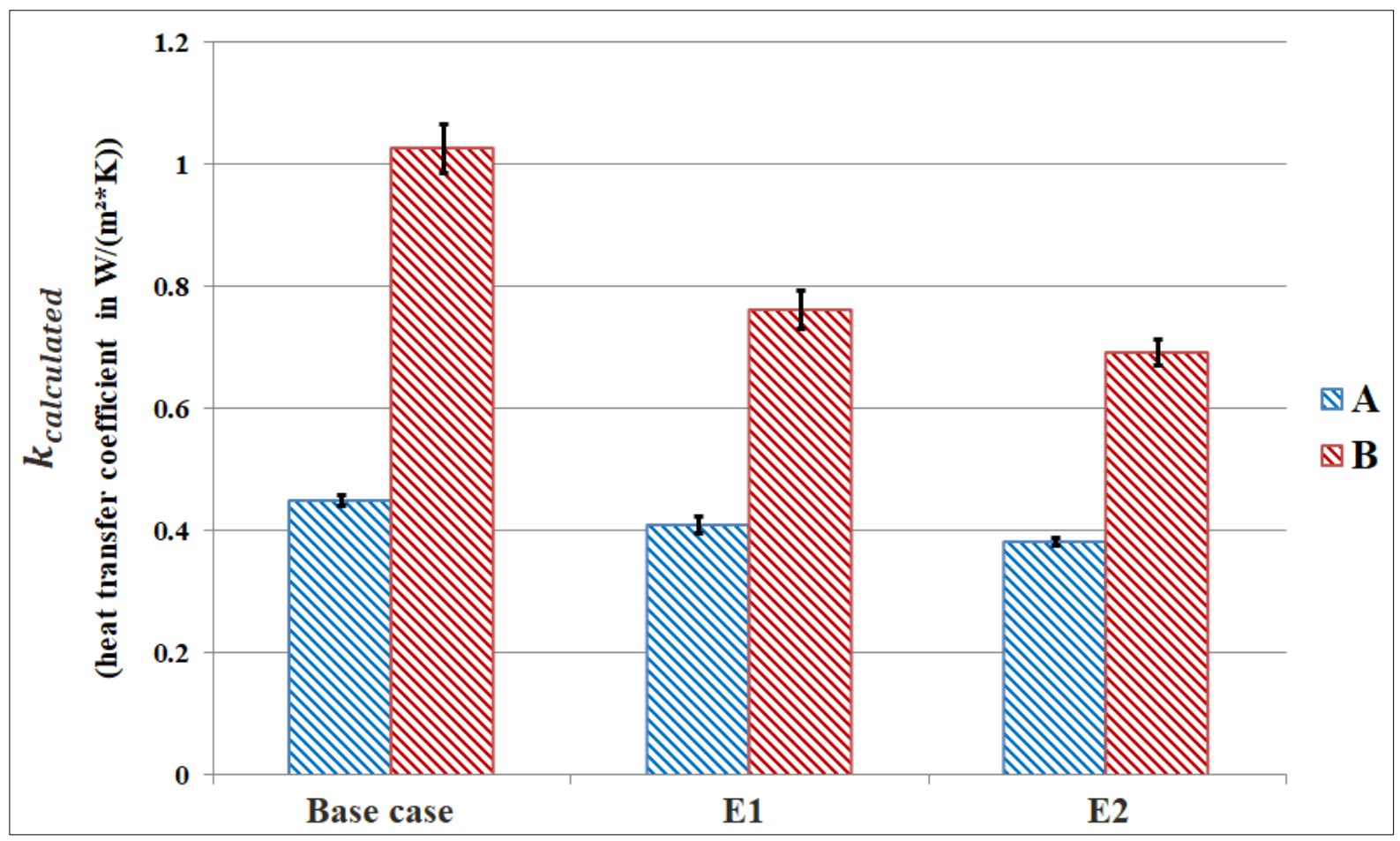

Figure 9 shows that $k_{\text {calculated }}$ of $\mathrm{A}$ and $\mathrm{B}$ decreases with the application of additional layers of insulation. Declining $k$ gradually levels out with additional layers of insulation, demonstrated by a flattening course of the $k_{\text {calculated }}$ throughout the three scenarios. The mean $k_{\text {calculated }}$ of appliance A decreases by $15 \%$ between the base case and E2. Contrary to appliance A, the mean $k_{\text {calculated }}$ of $B$ decreases more pronouncedly with almost $32 \%$ throughout successive insulation improvements. Additionally, the standard deviation of the data for appliance B is at least four times larger than that of appliance $\mathrm{A}$ for every scenario. Similar to the correlation between $\tau_{I}$ and the $E C$ in the case of simulated insulation improvement, the correlation between $k$ and the $E C$ was further evaluated, presented

by 


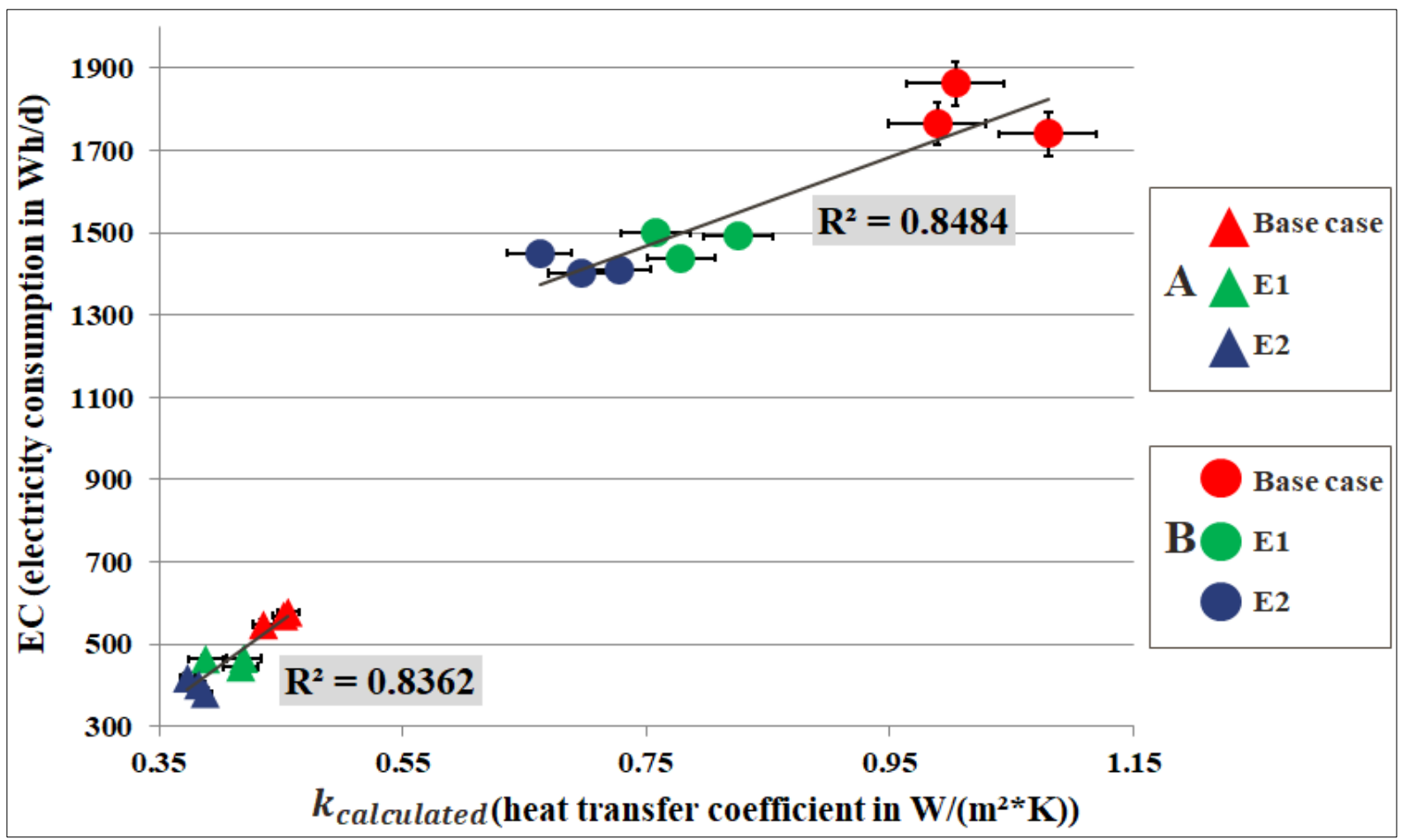

Figure 10. Again, $k$ is expressed as $k_{\text {calculated }}$.

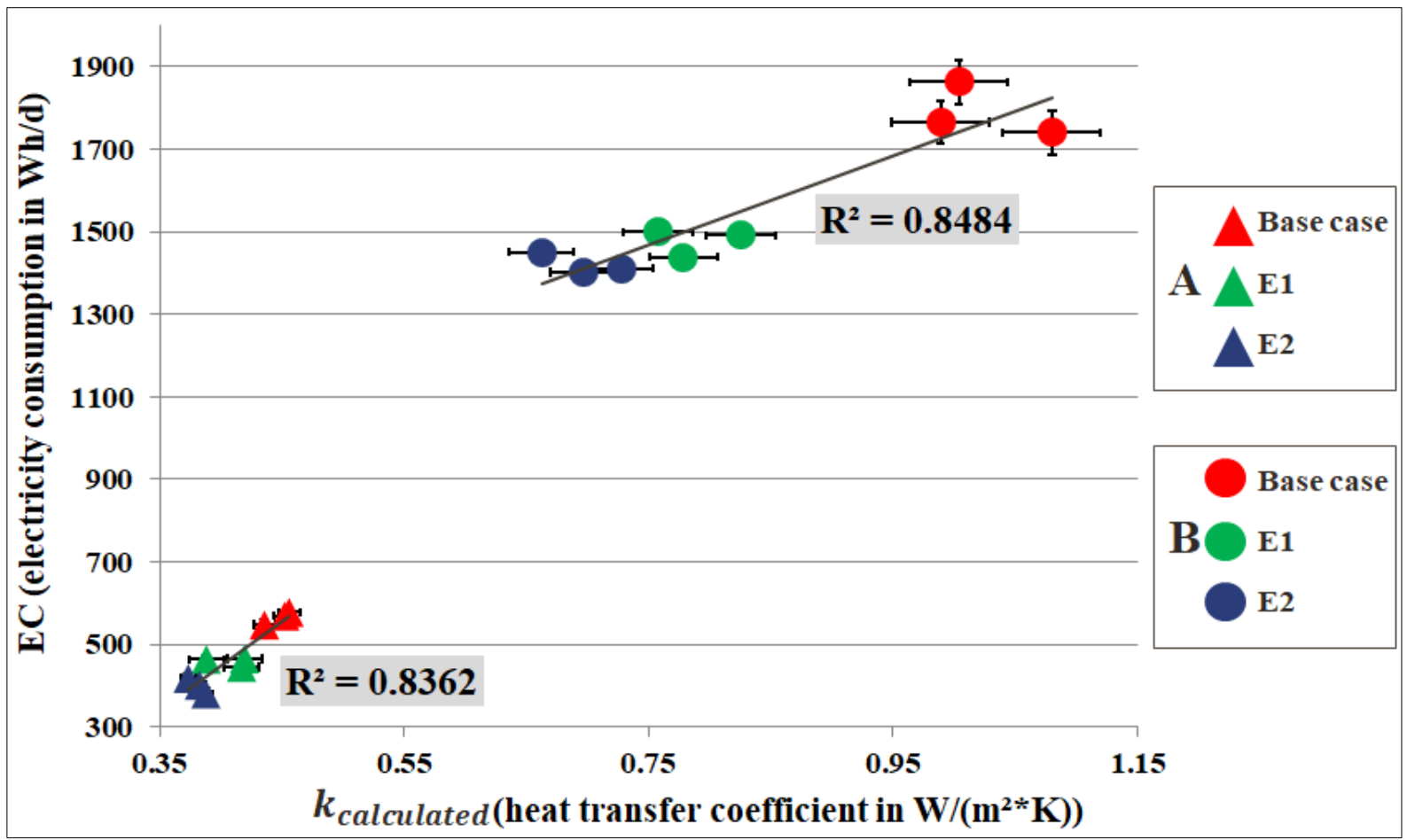

Figure 10: Correlation between $\boldsymbol{k}_{\text {calculated }}$ and EC in the case of simulated insulation improvement

Appliance A shows small standard deviations for both changes in $E C$ and $k_{\text {calculated }}$ in the event of simulated insulation improvement. 


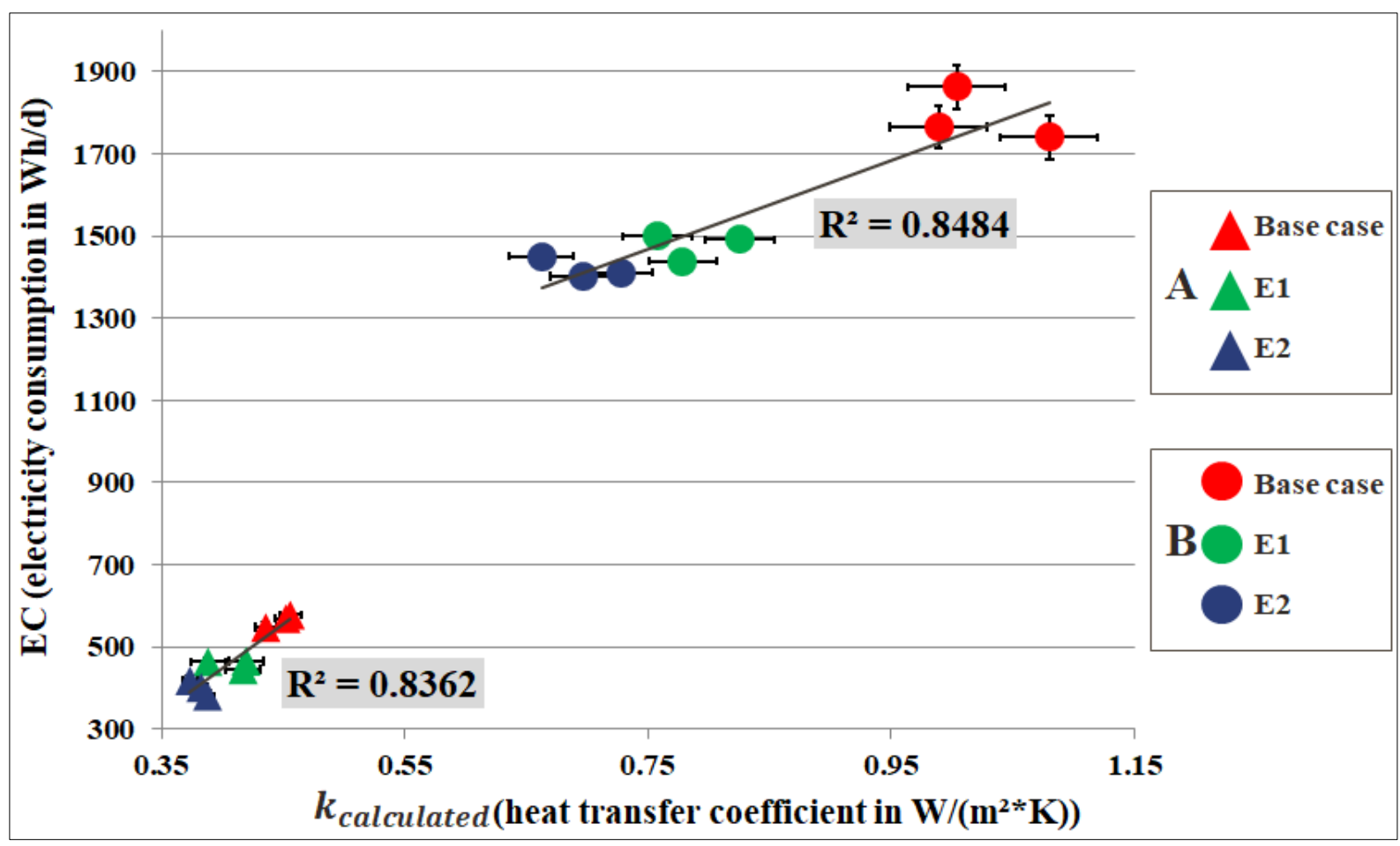

Figure 10 further gives the straight-line correlations for test devices $\mathrm{A}$ and $\mathrm{B}$, indicating a high $R^{2}$ for both appliances. The goodness of fit shows a distinct correlation between the $k_{\text {calculated }}$ and EC. Regarding the age-related efficiency loss of domestic refrigeration appliances, preliminary results imply that the $E C$ increases over time due to a rise in heat transfer through the multi-layered compartment walls.

\section{Discussion}

At first, the degradation of PUR rigid foam was investigated based on the stand-alone ageing of sealed samples at a constant $T_{a}$ for about a year. All samples comprised of closed-cell PUR only and were encased by aluminium foil. Both the cell gas composition and the $\lambda_{P U R}$ were determined several times within the investigation period. We found that cell gases of moulded PUR rigid foam samples diffuse out of the cells and are gradually replaced by nitrogen and oxygen. The $\lambda_{P U R}$ simultaneously increased by $15 \%$ within the investigation period. Wilkes et al. [46-[48], Albrecht and Khoukhi et al. [37-[39] investigated a similar large initial increase in the $\lambda_{P U R}$ of varying test samples as a result of gas exchange. The results are also in line with the findings of Fleurent et al. [[31] for changes of the $\lambda_{\text {PUR }}$ for samples with different facings, such as aluminium. We further found that if the closed-cell content was below $85 \%$ an ageing of the foam insulation performance was quite rapid. The reason for this was a gas-diffusion-controlled, hence, fast exchange of all cell gases (including cyclopentane). According to our own investigations an open-cell content below $10 \%$ leads to an increase of the $\lambda_{\text {PUR }}$ from $19.8 \mathrm{~mW} /(\mathrm{m} * K)$ up to $23.0 \mathrm{~mW} /(\mathrm{m} * K)$ (storage temperature: $70{ }^{\circ} \mathrm{C}$ ) within 7 days. In contrast, an open-cell content above $80 \%$ leads to an increase of the $\lambda_{P U R}$ up to $32.5 \mathrm{~mW} /(\mathrm{m} * K)$ 
within the same storage time of 7 days at $70{ }^{\circ} \mathrm{C}$. The cell gas analysis showed that air was the main cell gas in the latter case. There is evidence that the ageing increases in the event of fluctuating $T_{a}$, causing an expansion and contraction of floating gases $[29,[49,[55]$. It is anticipated that the increasing $\lambda_{P U R}$ flattens out after the first couple of years, depending on the time it takes the cell gases to reach a stable equilibrium $[8,[51]$. This course would be in line with the previous research results of Wilkes et al. [[48], Albrecht [37] and Wu et al. [44].

Second, the main research objective was to develop an innovative approach that specifies the state of insulation degradation intrinsic to household refrigerating appliances. Since the Bonn method constitutes an unprecedented approach, some imprecisions form the basis for future research. Regarding the methodological development, Newton's law of cooling (Equation (2)) was applied to derive a time constant test value $\left(\tau_{I}\right)$, subsequently used to calculate the heat transfer $\left(k_{\text {calculated }}\right)$ through the multi-layer compartment walls of domestic refrigerating appliances. Different from the temperature rise test reported in the IEC 62552-2 [64], the main intention of the Bonn method is to determine the influence of insulation degradation on the overall efficiency loss of refrigeration appliances over time.

One systematic uncertainty of the approach is related to the derivation of $\tau_{I}$. The test value does not only consider the heat conductivity through the multi-layer appliance walls, but also involves other heat dissipations. In fact, $\tau_{I}$ reflects an estimate of the overall $k$ of a test appliance. Potential penetrations of the insulation material by piping, heaters and associated wiring, cables, drain hole etc. depend on the type of construction and are likely to lead to additional heat gains. Penetrations are typically difficult to evaluate and can only be distinctly determined by prior deconstruction. The Bonn method assumes that these other factors remain constant over time. The effort to determine other factors would be large, especially since it is known that a majority of the $k$ bases on the actual effectiveness of the insulation material and its facings $[[9,[31,[49,[50]$. For instance, most of the electric wiring for appliances with digital temperature display is installed outside the foam-filled partition walls, whereas single cables of appliances with manual thermostat pass through the partition walls. It is general state of the art that cables and wiring are fixed to the wall insides, having a minimal impact on the insulation effectiveness. Another systematic uncertainty originates from the chosen resolution of time and temperature to record $T_{i}$ and $T_{a}$ during the application of the Bonn method. Test parameters have to be constant for test repetitions or test series in order to prevent a variability of the calculated $\tau_{I}$. Additionally, the range of the test interval to exclude multiple downstream effects after switching an appliance off (section 2.2.2.) needs to be constant for consecutive tests. The initial period of the test interval was discounted due to ongoing cooling effects of the evaporator, radiative heat exchange between the evaporator and the inside compartment walls, gas migration, pressure equalisation of the refrigeration system and potential condensation accumulation in the evaporator after switch-off. Unlike ongoing cooling effects, other downstream effects could hardly be measured. Excluding the first $20 \%$ of all temperature rise data from the relevant period reduces the uncertainty related to the aforementioned downstream effects. However, the duration of downstream effects 
varies for different types of appliances (refrigerators, freezers, fridge-freezer combinations) and depends on construction. Appliances $A$ and $B$, for instance, operate on the grounds of hermetic reciprocating compressors and have plate evaporators installed at the interior rear panels. Disregarding $20 \%$ of the temperature rise's initial values corresponds to a duration of at least $30 \mathrm{~min}$. To the best of our knowledge, this excludes uncertainties in $\tau_{I}$. Nevertheless, a deviating delimitation of the test interval would have influenced $\tau_{I}$.

Regarding the experiments simulating an improvement of the insulation, measurement uncertainties may either have been caused by the construction of $E 1$ and $E 2$ or manual fitting to appliances $A$ and B. As casings were constructed of single panels of XPS, minor damages to the casings in the assembly process could not be excluded. Additionally, the insulating covers were attached with strap belts and burdened with weights when applied to devices A and B. This ensured a good fit with the surface area. Neither strap belts nor weights have been changed throughout the test repetitions so that the same utilities have been used for fitting the covers to $A$ and $B$, respectively. The method applied to simulate an improved insulation performance is only applicable to refrigerating appliances with wire tube condensers. It is not applicable to appliances with skin condensers, commonly found on the appliance's back and both sides. For such appliances, the application of additional casings would inhibit the ability of the condensers to reject heat.

Concerning the applicability of the Bonn method, the approach can be applied to a range of different types of domestic refrigerating appliances, including refrigerators, freezers and fridge-freezer combinations. To thoroughly evaluate the influence of insulation degradation on the overall efficiency loss of refrigerating appliances, both changes in $E C$ and $\tau_{I}$ have to be determined by regular measurements on initially new appliances over several years. In this contribution, however, the Bonn method was applied to two inventory appliances (A and B), chosen due to appliance's age. This way, simulated insulation improvements could be executed to verify the methodological approach on the basis of successive experiments and to indicate which degradation can be expected for new appliances throughout their use phase. The application of the Bonn method to different refrigerating models varies slightly, depending on the construction. For instance, the condensation drain hole of fan-forced appliances with a remote evaporator or automatic defrosting, typically freezers, have no manually accessible drainage in the interior cavity. The drain holes of such appliances need to be plugged from the outside, at the back of the appliance over the drainer.

\section{Concluding remarks and outlook}

The ageing of household refrigeration appliances is caused by multiple sources and leads to degrading efficiency over time. The age-related degradation of the insulation is a key factor of decreasing efficiency. This study was based on experimental measurements concerning both the ageing of sealed samples of PUR rigid foam and the development of a non-destructive testing method. The ageing of test samples showed distinct changes in the cell gas composition and $\lambda_{P U R}$ 
within the first year of investigation. The cell gas contents of oxygen and nitrogen increased from approximately $4 \%$ and $1 \%$ to $23 \%$ and $39 \%$, respectively, whereas the cell gas content of carbon dioxide dropped to almost zero. Changes in the cell gas composition correspond to the increase in $\lambda_{\text {PUR }}$ of $15 \%$ within the investigation period.

The main contribution in this paper was the development of the Bonn method. The approach determines the overall insulation performance of a refrigerating appliance by deriving a time constant test value $\left(\tau_{I}\right)$, used to subsequently calculate the $k$ ( $\left.k_{\text {calculated }}\right)$ of the multi-layer compartment walls. Preliminary tests regarding the dependence of $\tau_{I}$ on $T_{a}$ show an independence of the test value from moderate $T_{a}$ variations. Further experiments simulating successive insulation improvements were conducted to investigate changes in $\tau_{I}$ and the $E C$ in the event of modified insulation properties, indicating almost congruent courses. Results suggest that a distinct correlation between the $E C$ and $\tau_{I}$ exists, validating the non-destructive approach. The physical relationship between $\tau_{I}$ and $k$ was further established. An important finding is the relationship between the $E C$ and the $k_{\text {calculated }}$ in the case of simulated insulation improvement, corresponding to the correlation between $E C$ and $\tau_{I}$. Therewith, the results give substantiated evidence that the efficiency loss of cooling appliances is largely influenced by insulation degradation over time.

The comprehensive investigation on the relationship between degrading foam insulation and efficiency loss is important, since the ageing performance of domestic refrigeration appliances is a topic with only limited research. In the future, comparative measurements to other methods (such as $k^{*} A$ ) are conceivable to determine the general measurement uncertainty of the Bonn method and to provide an assessment of impact these might have on results. The Bonn method can be used in multiple ways to provide valuable insights into the actual scale of insulation degradation and its associated consequences. One field of future application is to evaluate the effectiveness of varying insulation and facing materials used in the compartment walls to increase efficiency. Another field of application is with long-term investigations. Similar to the Bonn method, other test methods concerning the degradation of the door gasket and compressor-refrigerant circuit have been developed. A regular application of all three test methods to initially new appliances over several years holds the potential to thoroughly evaluate the extent to which the deterioration of each component affects the efficiency loss of the overall system over time. These are critical topics for many stakeholders and provide the basis for future research.

\section{Acknowledgements:}

This work was funded and supported by the German Federal Ministry for Economic Affairs and Energy (BMWi), project 'ALGE' (03ET1544A-E).

\section{Appendix:}




\section{Equation i:}

$$
\frac{1}{k \cdot A}=\left(\frac{1}{\alpha_{a}}+\frac{1}{\lambda_{x i}}+\frac{1}{\lambda_{P U R}}+\frac{1}{\lambda_{y i}}+\frac{1}{\alpha_{i}}\right)=\sum_{m}^{n}\left(\frac{1}{\alpha_{a, m} \cdot A_{m}}+\frac{1}{\alpha_{i, m} \cdot A_{m}}+\sum_{j}^{k} \frac{d_{j}}{\lambda_{j} \cdot A_{j}}\right)
$$

Equation forms the calculation of the heat transfer coefficient in relation to the cross-sectional surface area. It takes the influence of air currents on different appliance surfaces and thicknesses of the inner and outside cladding with varying material layers into account.

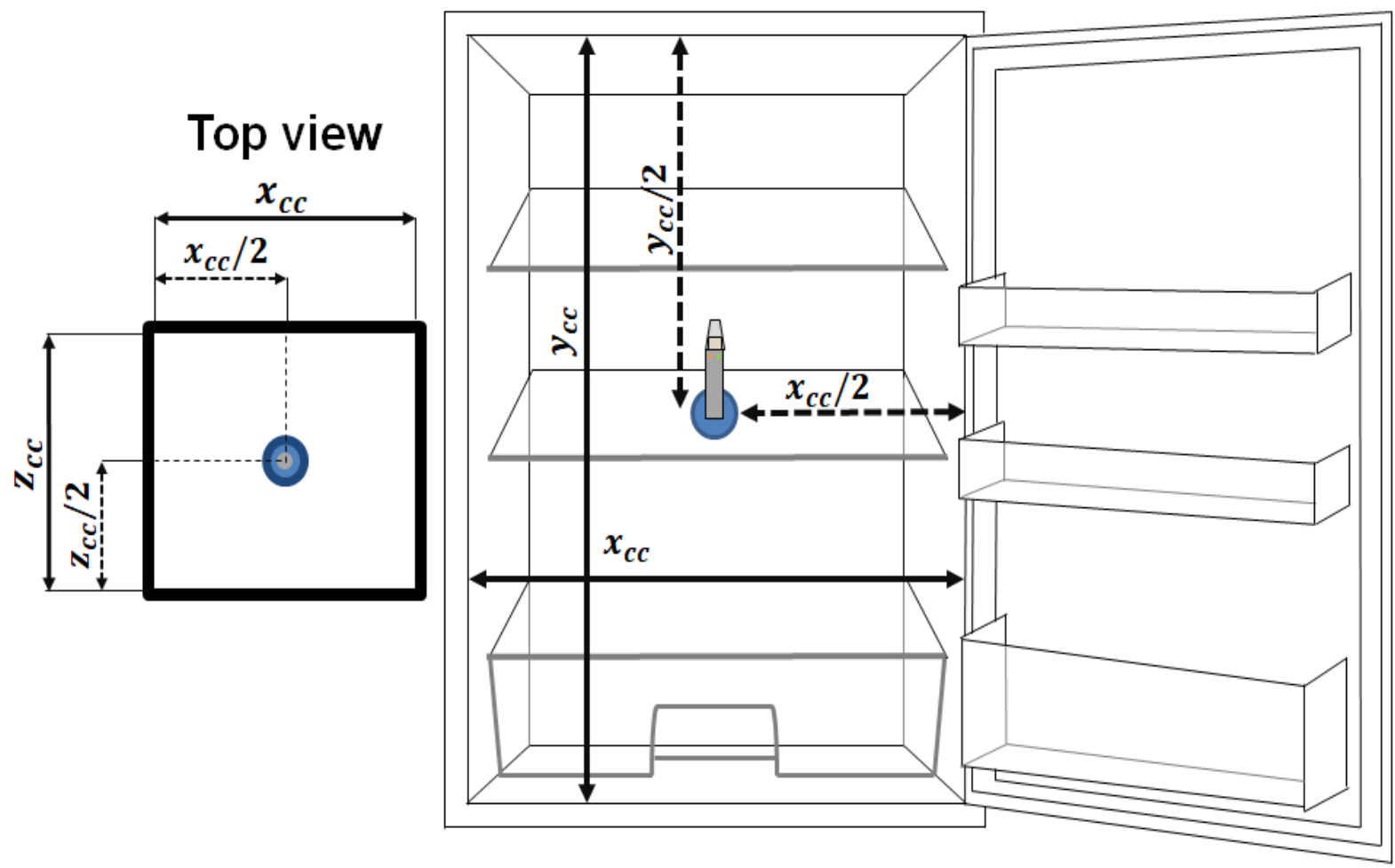

Figure i: Positioning of temperature sensors for appliances with one compartment 

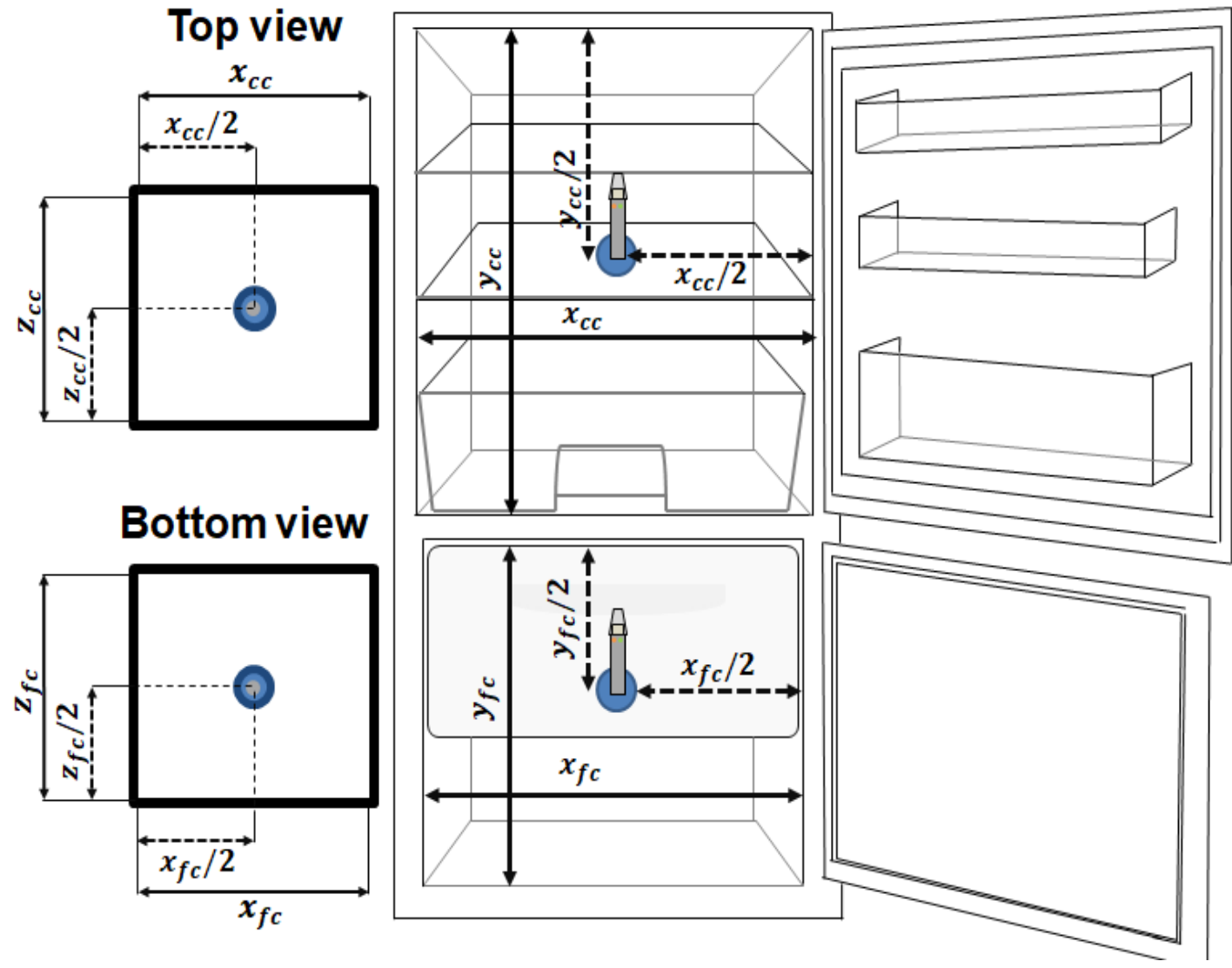

Figure ii: Positioning of temperature sensors for appliances with multiple compartments

Table ii: Ambient temperatures for successive tests of simulated insulation improvements

\begin{tabular}{|c|c|c|c|}
\hline & & $\begin{array}{c}\text { Figure } \mathbf{6}^{*} \\
\text { Application of the Bonn method }\end{array}$ & $\begin{array}{c}{\text { Figure } \mathbf{7}^{*}}^{E C \text { measurements }}\end{array}$ \\
\hline \multirow{3}{*}{$\frac{\overline{0}}{\frac{0}{0}}$} & Base Case & $19.55^{\circ} \mathrm{C}$ & $24.68^{\circ} \mathrm{C}$ \\
\hline & E1 & $19.22^{\circ} \mathrm{C}$ & $24.59^{\circ} \mathrm{C}$ \\
\hline & E2 & $19.49^{\circ} \mathrm{C}$ & $24.82^{\circ} \mathrm{C}$ \\
\hline \multirow{3}{*}{$\frac{N}{0}$} & Base Case & $19.10^{\circ} \mathrm{C}$ & $24.83^{\circ} \mathrm{C}$ \\
\hline & E1 & $19.56^{\circ} \mathrm{C}$ & $24.71^{\circ} \mathrm{C}$ \\
\hline & E2 & $20.00{ }^{\circ} \mathrm{C}$ & $24.59^{\circ} \mathrm{C}$ \\
\hline \multirow{3}{*}{$\underset{0}{\infty}$} & Base Case & $19.50^{\circ} \mathrm{C}$ & $25.12^{\circ} \mathrm{C}$ \\
\hline & E1 & $19.59^{\circ} \mathrm{C}$ & $24.73^{\circ} \mathrm{C}$ \\
\hline & E2 & $20.12^{\circ} \mathrm{C}$ & $24.84^{\circ} \mathrm{C}$ \\
\hline
\end{tabular}

* Appliances $A$ and $B$ were tested at the same time throughout all experiments concerning simulated insulation improvements (Bonn method and EC measurements).

All ambient temperatures $\left(T_{a}\right)$ are given as the average measured test room ambient temperature during the test period. 


\section{References:}

[1] J.S. Brown, P.A. Domanski, Review of alternative cooling technologies, Appl. Therm. Eng. 64 (2014) 252-262. https://doi.org/10.1016/j.applthermaleng.2013.12.014.

[2] C. James, B.A. Onarinde, S.J. James, The use and performance of household refrigerators: a review, Compr. Rev. Food Sci. Food Saf. 16 (2017) 160-179. https://doi.org/10.1111/1541$\underline{4337.12242 .}$.

[3] R.S. Mithishita, E.M. Barreira, C.O.R. Negrão, C.J.L. Hermes, Thermoeconomic design and optimization of frost-free refrigerators, Appl. Therm. Eng. 50 (2013) 1376-1385. https://doi.org/10.1016/j.applthermaleng.2012.06.024.

[4] German Federal Statistical Office, Equipment of households with electrical household appliances and others. https://www.destatis.de/EN/Themes/Society-Environment/IncomeConsumption-Living-Conditions/Equipment-Consumer-Durables/Tables/liste-equipmenthouseholds-electrical--household-appliance-others-germany, 2019 (accessed 22 August 2019).

[5] Official Journal of the European Union, Directive 2009/125/EC of the European Parliament and of the Council of 21 October 2009 establishing a framework for the setting of ecodesign requirements for energy-related products. http://data.europa.eu/eli/dir/2009/125/2012-12-04, 2019 (accessed 21 August 2019).

[6] L.F. Cabeza, D. Urge-Vorsatz, M. Mc Neil, C. Barreneche, S. Serrano. Investigating greenhouse challenge from growing trends of electricity consumption through home appliances in buildings. Renew. Sust. Energ. Rev. 36 (2014) 188-193. https://doi.org/10.1016/i.rser.2014.04.053.

[7] M. Weiss, M.K. Patel, M. Junginger, K. Blok, Analyzing price and efficiency dynamics of large appliances with the experience curve approach, Energ. Pol. 38 (2010) 770-783. https://doi.org/10.1016/j.enpol.2009.10.022.

[8] D. Bhattacharjee, P.W. Irwin, J.R. Booth, J.T. Grimes, The acceleration of foam aging by thin-slicing: some interpretations and limitations, J. Build. Phys. 17 (1994) 219-237. https://doi.org/10.1177/109719639401700305.

[9] U. Berardi, The impact of aging and environmental conditions on the effective thermal conductivity of several foam materials, Energy. 182 (2019) 777-794. https://doi.org/10.1016/..energy.2019.06.022.

[10] J. Geppert, R. Stamminger, Analysis of effecting factors on domestic refrigerators' energy consumption in use, Energ. Convers. Manage. 76 (2013) 794-800. http://dx.doi.org/10.1016/j.enconman.2013.08.027.

[11] L. Harrington, L. Aye, B. Fuller, Impact of room temperature on energy consumption of household refrigerators: Lessons from analysis of field and laboratory data. Appl. Energy. 211 (2018) 346-357. https://doi.org/10.1016/i.apenergy.2017.11.060.

[12] L. Harrington, L. Aye, R.J. Fuller, Opening the door on refrigerator energy consumption: quantifying the key drivers in the home. Energ. Effic. 11 (2018) 1519-1539. https://doi.org/10.1007/s12053-018-9642-8.

[13] J. Geppert, R. Stamminger, Do consumers act in a sustainable way using their refrigerator? The influence of consumer real life behaviour on the energy consumption of cooling appliances. Int. J. Consum. Stud. 34 (2010) 219-227. https://doi.org/10.1111/j.14706431.2009.00837.x. 
[14] A. Biglia, A.J. Gemmell, H.J. Foster, J.A. Evans, Temperature and energy performance of domestic cold appliances in households in England, Int. J. Refrig. 87 (2017) 172-184. https://doi.org/doi:10.1016/.i.jrefrig.2017.10.022.

[15] N. Isaacs, M. Camilleri, L. French, A. Pollard, K. Saville-Smith, R. Fraser, P. Rossouw, J. Jowett, Energy use in New Zealand households - report on the year 10 analysis for the household energy end-use project (HEEP). SR155 (2006), Wellington, New Zealand, http://www.branz.co.nz/books popup.php?id=18493.

[16] J. Greenblatt, A. Hopkins, V. Letschert, M. Blasnik, Energy use of US residential refrigerators and freezers: Function derivation based on household and climate characteristics, Energ. Effic. 6 (2013) 135-162. https://doi.org/10.1007/s12053-012-9158-6.

[17] Stiftung Warentest, Stromhunger wächst, test. 2013 (2013) 60.

[18] A. Elsner, M. Mueller, A. Paul, J. Vrabec. Zunahme des Stromverbrauchs von Haushaltskühlgeräten durch Alterung. DKV-Tagung 2013, AA II.2. ISBN:9783932715495.

[19] R. Perkins, L. Cusco, J. Howley, A. Laesecke, S. Matthes, M.L.V. Ramires, Thermal conductivities of alternatives to CFC-11 for foam insulation, J. Chem. Eng. Data. 46 (2001) 428-432. https://doi.org/10.1021/je990337k.

[20] D. Daems, D. Rosbotham, S.N. Singh, M.V. Franco, Factors affecting the long term dimensional stability of rigid foam for the construction industry, J. Cell. Plast. 32 (1996) 485500. https://doi.org/10.1177/0021955X9603200505.

[21] J.A. King, D.D. Latham, J.C. Ackley, Relationship of k-factor versus density for various appliance foam formulations containing next generation blowing agents, J. Cell. Plast. 32 (1996) 355-366. https://doi.org/10.1177/0021955X9603200403.

[22] J. Cao, C. Chen, G. Gao, H. Yang, Y. Su, M. Bottarelli, M. Cannistraro, G. Pei, Preliminary evaluation of the energy-saving behavior of a novel household refrigerator, J. Renew. Sust. Energ. 11 (2019). https://doi.org/10.1063/1.5054868.

[23] S. Woo, M. Pecht, D.L. O'Neal, Reliability design and case study of a refrigerator compressor subjected to repetitive loads, Int. J. Refrig. 32 (2009) 478-486. http://dx.doi.org/10.1016/i.jirefrig.2008.07.006.

[24] C. Afonso, M. Castro, Air infiltration in domestic refrigerators: The influence of the magnetic seals conservation, Int. J. Refrig. $33 \quad$ (2010) 856-867. http://dx.doi.org/10.1016/j.ijrefrig.2009.12.007.

[25] F. Gao, S.S Naini, J. Wagner, R. Miller, An experimental and numerical study of refrigerator heat leakage at the gasket region, Int. J. Refrig. 73 (2017) 99-110. https://doi.org/10.1016/i.ijrefrig.2016.09.002.

[26] P. Bansal, E. Vineyarda, O. Abdelaziza, Advances in household appliances- A review, Appl. Therm. Eng. 31 (2011) 3748-3760. https://doi.org/10.1016/i.applthermaleng.2011.07.023.

[27] F. Ochs, W. Heidemann, H. Müller-Steinhagen, Effective thermal conductivity of moistened insulation materials as a function of temperature. Int. J. Heat Mass. Transf. 51 (2008) 539552. https://doi.org/10.1016/j.ijheatmasstransfer.2007.05.005.

[28] U. Berardi, L. Tronchin, M. Manfren, B. Nastasi, On the effects of variation of thermal conductivity in buildings in the Italian construction sector, Energies. 11 (2018) 872. https://doi.org/10.3390/en11040872.

[29] M. Budaiwi, A. Abdou, M. Al-Homoud, Variations of thermal conductivity of insulation materials under different operating temperatures: impact on envelope-induced cooling load, J. Archit. Eng. 8 (2002) 125-135. https://doi.org/10.1061/(ASCE)1076-0431(2002)8:4(125). 
[30] M.S. Al-Homoud, Performance characteristics and practical applications of common building thermal insulation materials, Build. Environ. 40 (2005) 353-366. https://doi.org/10.1016/i.buildenv.2004.05.013.

[31] $\mathrm{H}$. Fleurent, S. Thjs, The use of pentanes as blowing agent in rigid polyurethane foam, J. Cell. Plast. 31 (1995) 580-599. https://doi.org/10.1177/0021955X9503100606.

[32] A.A. Abdou, I.M. Budaiwi, Comparison of thermal conductivity measurements of building insulation materials under various operating temperatures, J. Build. Phys. 29 (2005) 171184. https://doi.org/10.1177/1744259105056291.

[33] K-E. Wagner, Simulation und Optimierung des Wärmedämmvermögens von PURHartschaum, Wärme- und Stofftransport sowie mechanische Verformung, Dissertation, Stuttgart (Germany): I. f. Stuttgart, Ed, 2002. http://dx.doi.org/10.18419/opus-1579.

[34] H. Macchi-Tejeda, H. Opatovà, J. Guilpart, Contribution to the gas chromatographic analysis for both refrigerants composition and cell gas in insulating foams - Part II: Aging of insulating foams, Int. J. Refrig. 30 (2007) 338-344. http://dx.doi.org/10.1016/j.ijrefrig.2006.04.004.

[35] J. Berardia, J. Madzarevic, Microstructural analysis and blowing agent concentration in aged polyurethane and polyisocyanurate foams, Appl. Therm. Eng. 164 (2020) 114440. https://doi.org/10.1016/j.applthermaleng.2019.114440.

[36] J.E. Christian, A. Desjarlais, R. Graves, Five-year field study confirms accelerated thermal aging method for polyisocyanurate insulation, J. Cell. Plast. 34 (1998) 39-64. https://doi.org/10.1177/0021955X9803400103.

[37] W. Albrecht, Change over time in the thermal conductivity of ten-year-old PUR rigid foam boards with diffusion-open facings, Cell. Polym. 23 (2004) 161-172. https://doi.org/10.1177/026248930402300303.

[38] W. Albrecht, Cell-gas composition - An important factor in the evaluation of long-term thermal conductivity in closed-cell foamed plastics, Cell. Polym. 19 (2000) 319-331.

[39] M. Khoukhi,N. Fezzioui, B. Draoui, L. Salah, The impact of changes in thermal conductivity of polystyrene insulation material under different operating temperatures on the heat transfer through the building envelope, Appl. Therm. Eng. 105 (2016) 669-674. https://doi.org/10.1016/j.applthermaleng.2016.03.065.

[40] P. Glouannec, M. Benoit, G. Delamarre, Y. Grohens, Experimental and numerical study of heat transfer across insulation wall of a refrigerated integral panel van, Appl. Therm. Eng. 73 (2014) 196-204. https://doi.org/10.1016/..applthermaleng.2014.07.044.

[41] H. Seifert, A. Biedermann, Long-term energy efficiency of PU insulation for refrigeration, in: Conference Proceedings, Polyurethanes Conference 2000: Defining the future through technology, CRC Press, Boston (Massachusetts), 2000, pp. 429-435.

[42] G.C.J. Bart, G.M.R. Du Cauzé de Nazelle GMR. Certification of thermal conductivity aging of PUR foam, J. Cell. Plast. 29 (1993) 29-42. https://doi.org/10.1177/0021955X9302900102.

[43] S.A. Al-Ajlan, Measurements of thermal properties of insulation materials by using transient plane source technique, Appl. Therm. Eng. 26 (2006) 2184-2191. https://doi.org/10.1016/i.applthermaleng.2006.04.006.

[44] J.W. Wu, W.F. Sung, H.S. Chu, Thermal conductivity of polyurethane foams. Int. J. Heat Mass Transf. 42 (1999) 2211-2217. https://doi.org/10.1016/S0017-9310(98)00315-9.

[45] A. Galakhova, M. Santiago-Calvo, J. Tirado-Mediavilla, M. Villafañe, A. Rodríguez-Pérez, G. Riess, Identification and quantification of cell gas evolution in rigid polyurethane foams by novel GCMS methodology, Polymers (Basel). $11 \quad$ (2019) 1192. https://doi.org/10.3390/polym11071192. 
[46] K.E. Wilkes, F.J. Weaver, W.A. Gabbard, Aging of polyurethane foam insulation in simulated refrigerator panels -one-year results with third-generation blowing agents, J. Cell. Plast. 37 (2001) 400-428. http://doi.org/10.1106/N9XJ-PKE1-N3UV-DWJQ.

[47] K.E. Wilkes, D.W. Yarbrough, W.A. Gabbard, G.E. Nelson, J.R. Booth. Aging of polyurethane foam insulation in simulated refrigerator panels - three-year results with third-generation blowing agents, J. Cell. Plast. 38 (2002) 317-339. https://doi.org/10.1177/0021955X02038004142.

[48] K.E. Wilkes, D.W. Yarbrough, G. Nelson, Aging of Polyurethane Foam Insulation in Simulated Refrigerator Panels - Four-Year Results with Third-Generation Blowing Agents, J. of Cell. Plast. 38 (2003). 10.1177/0021955X02038004142.

[49] M. Bogdan, J. Hoerter, J.O. Moore, Meeting the insulation requirements of the building envelope with polyurethane and polyisocyanurate foam, J. Cell. Plast. 41 (2005) 41-56. https://doi.org/10.1177/0021955X05049869.

[50] M. Pfundstein, R. Gellert, M. Spitzner, A. Rudolphi, Insulating materials - Principles, materials, applications, Edition Detail; Walter de Gruyter. Berlin, Germany, 2008.

[51] H. Zhang, W-Z. Fang, W-Q. Tao, Y-M. Li, Experimental study of the thermal conductivity of polyurethane foams, Appl. Therm. Eng. 115 (2017) 528-538. http://dx.doi.org/10.1016/j.applthermaleng.2016.12.057.

[52] F. Ozkadi, 2001. The effect of thermal aging polyurethane to increasing the energy consumption of refrigerator and freezer, in: al., P.B.e. (Ed.), Energy Efficiency in Househould Appliances and Lighting. Springer-Verlag, Berlin-Heidelberg, Germany, pp. 114-121.

[53] H. Ozkan, E. Demirtas, U. Kilic, Arcelik Anonim Sirketi, A refrigerator comprising a plastic inner lining, patent document - WO 2019/007829 A1, WIPO | PCT, 10.01.2019.

[54] H. Ozkan, E. Demirtas, M. Sezer, O. Kaymakci, U. Kilic, Arcelik Anonim Sirketi, A refrigerator comprising a plastic inner lining, patent document - WO 2019/007030 A1, WIPO | PCT, 10.01.2019.

[55] M. Khoukhi, A. Hassan, S. A. Saadi, S. Abdelbaqi, A dynamic thermal response on thermal conductivity at different temperature and moisture levels of EPS insulation, Case Stud. Therm. Eng. 14 (2019) 100481. https://doi.org/10.1016/j.csite.2019.100481.

[56] R. Saidur, H.H. Masjuki, I.A. Choudhury, Role of ambient temperature, door opening, thermostat setting position and their combined effect on refrigerator-freezer energy consumption, Energ. Convers. Manag. 43 (2002) 845-854. https://doi.org/10.1016/S01968904(01)00069-3.

[57] O. Laguerre, Heat transfer and air flow in a domestic refrigerator. Mathematical modelling of food processing, Mohammed M. Farid (ed.), CRC Press, 445-474, 2010, Contemp. Food Eng. https://hal.archives-ouvertes.fr/hal-00583230.

[58] Ecodesign \& Labelling Review Household Refrigeration - Preparatory/review study, Commission Regulation (EC) No. 643/2009 and Commission (Delegated) Regulation $\quad$ (EU) 1060/2010, https://www.eupnetwork.de/fileadmin/user upload/2015/Household Refrigeration Review TASK 16 DRA FT REPORT 20151114.pdf, 2019 (accessed 20.12.2019).

[59] O. Laguerre, D. Flick, Heat transfer by natural convection in domestic refrigerators, J. Food Eng. 62 (2004) 79-88. https://doi.org/10.1016/S0260-8774(03)00173-0.

[60] F. Stefano, M. Presutto, R. Stamminger, R. Scialdoni, W. Mebane, R. Esposito, Preparatory studies for eco-design requirements of EuPs (Tender TREN/D1/40-2005) LOT13: Domestic refrigerators and freezers. https://www.eupnetwork.de/fileadmin/user upload/Lot 13 Final Report Taks 3-5.pdf, 2019 (accessed 10 
Mai 2019).

[61] R. Xiao, Y. Zhang, X. Liu, Z. Yuan, A life-cycle assessment of household refrigerators in China, J. Clean Prod. 95 (2015) 301-310. http://dx.doi.org/10.1016/.j.jclepro.2015.02.031.

[62] R.H.S. Winterton, Newton's law of cooling, Contemp. Phys. 40 (1999) 205-212. https://doi.org/10.1080/001075199181549.

[63] M. Vollmer, Newton's Law of Cooling revisited, Eur. J. Phys. 30 (2009) 1063-1084. https://doi.org/10.1088/0143-0807/30/5/014.

[64] IEC 62552-2: Household refrigerating appliances - Characteristics and test methods - Part 2: Performance requirements (Annex C), IEC, 2014, p.37.

[65] DIN EN 62552:2013, Household refrigerating appliances-characteristics and test methods (IEC 62552:2007, modified+corrigendum Mar. 2008), Beuth Verlag, 2013, Berlin. 